\title{
Anomalous Pseudocapacitive Behavior of a Nanostructured, Mixed- Valent Manganese Oxide Film for Electrical Energy Storage
}

\author{
Min-Kyu Song, ${ }^{\dagger, \#}$ Shuang Cheng, ${ }^{\dagger, \#}$ Haiyan Chen, ${ }^{\ddagger}$ Wentao Qin, ${ }^{\dagger}$ Kyung-Wan Nam, ${ }^{\S}$ Shucheng Xu,
} Xiao-Qing Yang, ${ }^{\S}$ Angelo Bongiorno," Jangsoo Lee, ${ }^{\perp}$ Jianming Bai, ${ }^{\text {IL }}$ Trevor A. Tyson, Jaephil Cho, ${ }^{\perp}$ and Meilin $\mathrm{Liu}^{*}, \dagger, \#$

${ }^{\dagger}$ School of Materials Science and Engineering, Center for Innovative Fuel Cell and Battery Technologies, Georgia Institute of Technology, 771 Ferst Drive, Atlanta, Georgia 30332-0245, United States

${ }^{\ddagger}$ Department of Physics, New Jersey Institute of Technology, Newark, New Jersey 07102, United States

${ }^{\S}$ Chemistry Department, Brookhaven National Laboratory, Upton, New York 11973, United States

"School of Chemistry and Biochemistry, Georgia Institute of Technology, 901 Atlantic Drive, Atlanta, Georgia 30332-0400, United States

${ }^{\perp}$ Interdisciplinary School of Green Energy, Ulsan National Institute of Science \& Technology (UNIST), 701-11,100 Banyeon-ri, Eonyang-eup, Ulju-gun, Ulsan, Korea, 689-798

${ }^{\text {II } H i g h ~ T e m p e r a t u r e ~ M a t e r i a l s ~ L a b o r a t o r y, ~ O a k ~ R i d g e ~ N a t i o n a l ~ L a b o r a t o r y, ~ O a k ~ R i d g e, ~ T e n n e s s e e ~ 37831, ~ U n i t e d ~ S t a t e s ~}$

\section{Supporting Information}

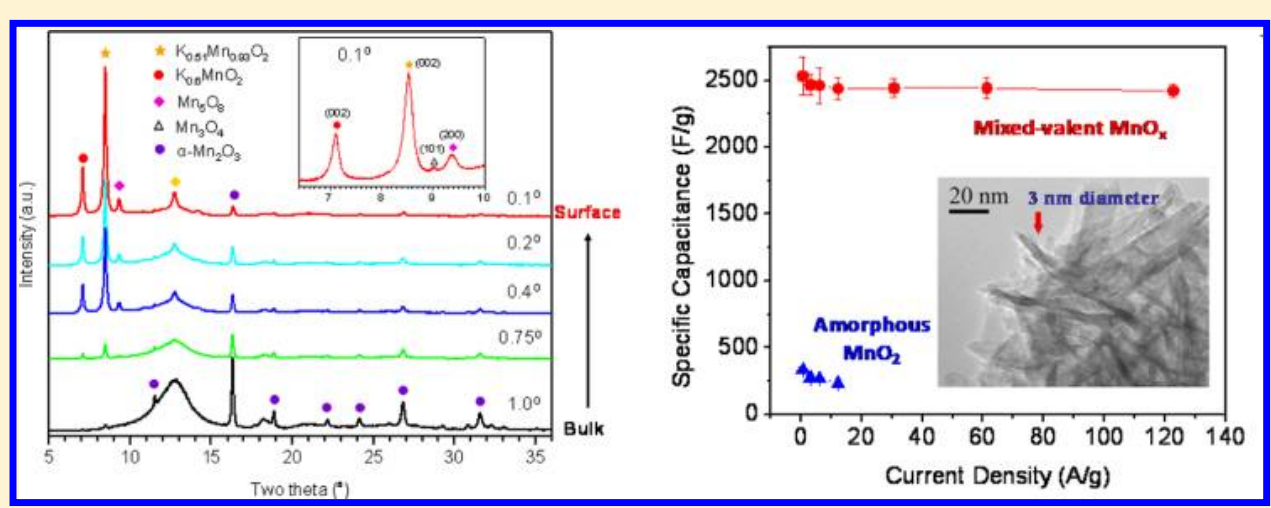

ABSTRACT: While pseudocapacitors represent a promising option for electrical energy storage, the performance of the existing ones must be dramatically enhanced to meet today's ever-increasing demands for many emerging applications. Here we report a nanostructured, mixed-valent manganese oxide film that exhibits anomalously high specific capacitance ( $\sim 2530 \mathrm{~F} / \mathrm{g}$ of manganese oxide, measured at $0.61 \mathrm{~A} / \mathrm{g}$ in a two-electrode configuration with loading of active materials $\sim 0.16 \mathrm{mg} / \mathrm{cm}^{2}$ ) while maintaining excellent power density and cycling life. The dramatic performance enhancement is attributed to its unique mixedvalence state with porous nanoarchitecture, which may facilitate rapid mass transport and enhance surface double-layer capacitance, while promoting facile redox reactions associated with charge storage by both $\mathrm{Mn}$ and $\mathrm{O}$ sites, as suggested by in situ X-ray absorption spectroscopy (XAS) and density functional theory calculations. The new charge storage mechanisms (in addition to redox reactions of cations) may offer critical insights to rational design of a new-generation energy storage devices.

KEYWORDS: Energy storage, electrochemical capacitors, mixed-valent compounds, enhanced pseudocapacitance, in situ X-ray absorption spectroscopy

$\mathrm{W}^{\mathrm{s}}$ hile the application of existing batteries is often limited by low power, short cycle life, and long charging time, ${ }^{1}$ the use of conventional capacitors suffers from inadequate energy density. Pseudocapacitors may bridge the gap between batteries and capacitors. ${ }^{2}$ Unlike electrochemical double layer capacitors (EDLCs), which store electrical energy by accumulation of ions on electrode surface, ${ }^{3}$ pseudocapacitors make use of fast redox reactions or phase changes on the surface or subsurface of electrodes, ${ }^{4-6}$ offering much higher energy densities than EDLCs. However, the rate capability and cycling stability of pseudocapacitors are perceived to be inferior to those of EDLCs and the energy density to be much lower than those of available batteries. To overcome these limitations, considerable efforts have been devoted to the creation of new

Received: March 12, 2012

Revised: June 3, 2012

Published: June 10, 2012 


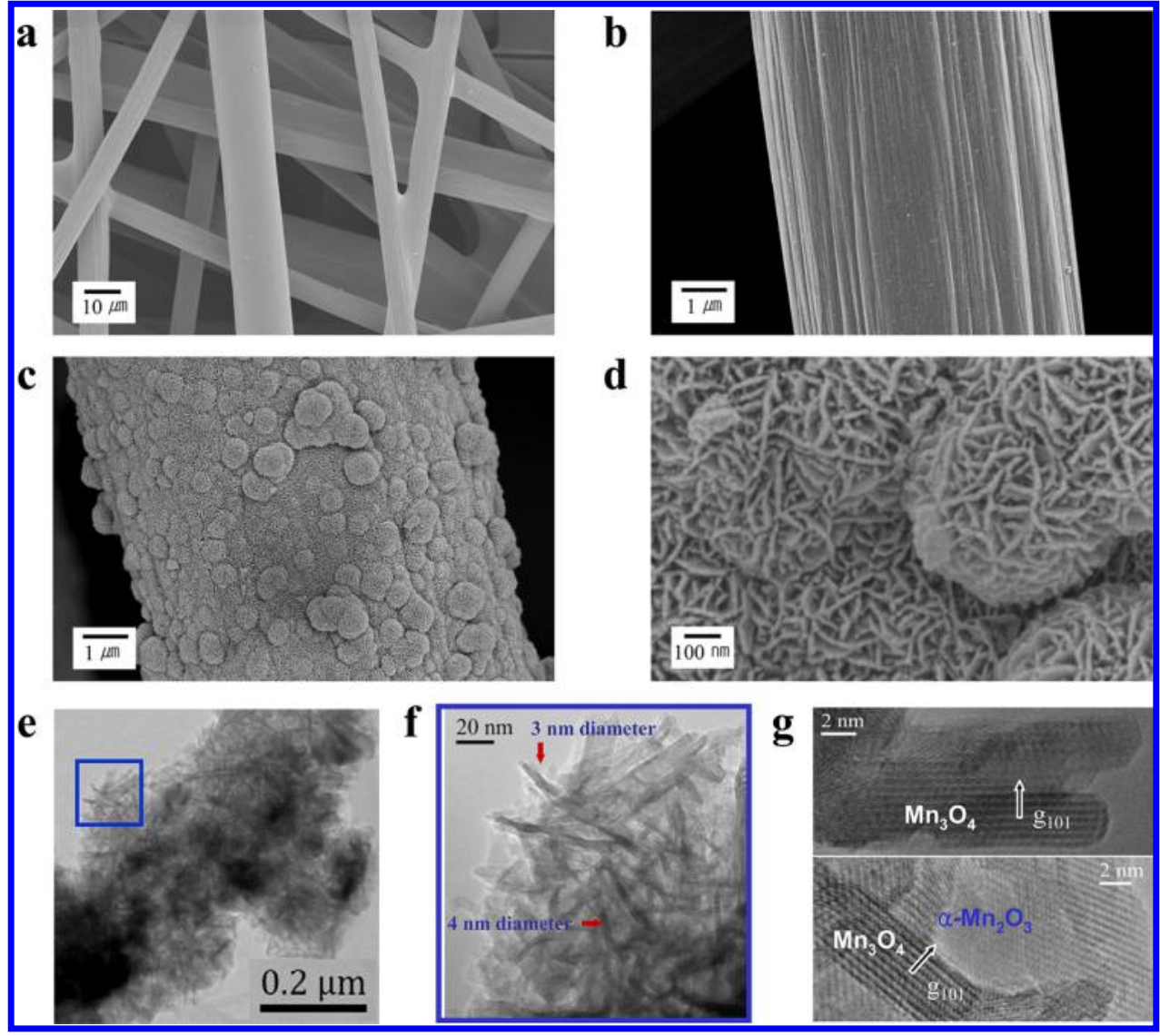

Figure 1. Electron microscopy analysis. (a) SEM image of carbon fiber paper (CFP) before coating showing 3D interconnected, porous structures. (b) SEM image of a carbon fiber before coating. (c) SEM image of a carbon fiber after conformal coating of $\mathrm{MnO}_{x}$ for $30 \mathrm{~min}$. (d) SEM image of the $\mathrm{MnO}_{x}$ coating annealed at $400{ }^{\circ} \mathrm{C}$ in air for $2 \mathrm{~h}$. (e) TEM image of $\mathrm{MnO}_{x}$ coating annealed at $400{ }^{\circ} \mathrm{C}$ in air for $2 \mathrm{~h}$. (f) A zoomed-in view of the blue square area in (e) showing a cluster of the needle-shaped crystals with diameters of $\sim 3$ to $\sim 4 \mathrm{~nm}$. (g) High-resolution TEM images showing the fringes of $\mathrm{Mn}_{3} \mathrm{O}_{4}$ and $\alpha-\mathrm{Mn}_{2} \mathrm{O}_{3}$ phase.

materials for pseudocapacitors. To date, however, the progress has been hindered largely by the lack of a profound understanding of the complex charge storage mechanisms related to intercalation of ions into electrode materials (of layered or channeled structures), reaction of ions with active electrode materials (to form new phases), and/or electrochemical adsorption of ions on electrode surfaces. It is traditionally believed that the pseudocapacitive behavior is associated primarily with the redox reactions of the cations (or changes in oxidation states of the cations) in electrode materials during operation. ${ }^{2}$ A suitable electrode material for high performance should promote fast, reversible redox reactions on the surface or subsurface. ${ }^{4,5}$

Among many materials investigated, since first reported by Goodenough group, ${ }^{7} \mathrm{MnO}_{2}$ has attracted much attention because it is abundant, inexpensive, and environmentally benign. While $\mathrm{MnO}_{2}$ has high theoretical capacitance 8 $(\sim 1370 \mathrm{~F} / \mathrm{g}$ as the oxidation state of $\mathrm{Mn}$ ion is changed from $4+$ to $3+$ over a potential window of $0.8 \mathrm{~V}$ ), its poor electronic conductivity often limits the electrode utilization; only the surface layers may participate in redox reactions. To overcome this limitation, $\mathrm{MnO}_{2}$ has been mixed with carbon particles or loaded onto carbon supports (including carbon nanotubes and graphene). ${ }^{9-16}$ To date, however, the reported specific capacitance of $\mathrm{MnO}_{2}$ varies from $\sim 150$ to $\sim 940 \mathrm{~F} / \mathrm{g}$ while the cycling stability still needs further improvement. Although higher specific capacitance $(\sim 1145 \mathrm{~F} / \mathrm{g})$ has been reported, ${ }^{17}$ the $\mathrm{MnO}_{2}$ was deposited into a nanoporous gold film ( $\sim 100 \mathrm{~nm}$ thick) and thus could be less competitive economically for practical applications. Further, the rate capability is still unsatisfactory for large-scale applications such as auxiliary power units for electric vehicles. With several oxidation states and a wide range of phases, manganese is a vital component in photosynthetic systems due to its unique ability to cycle between various oxidation states. ${ }^{18}$ In particular, manganese oxides can assume many different crystal structures upon accommodation of other metal cations. These complex features often give rise to unusual properties of manganese oxide. For example, the dramatic enhancement of catalytic activities toward oxidation of various organic compounds was attributed to the mixed-valence of manganese oxides. ${ }^{19,20}$

The investigation of mixed-valent compounds has a long and interesting history. Mixed-valent compounds contain donor and acceptor sites separated by a bridge. Since Prussian blue, a complex $\mathrm{Fe}(\mathrm{II}) / \mathrm{Fe}$ (III) cyanide, was first discovered in 1704, the study of mixed-valent compounds has had significant impacts in chemistry, physics, and biology. In particular, from the late 1960s, molecular mixed-valent compounds began to receive great attention due to their unique optical properties arising from significant electron transitions between donor and acceptor sites by absorbing specific wavelengths of visible light via intervalence charge transfer. The intense blue color of Prussian blue is related to the energy of the electron transfer from $\mathrm{Fe}(\mathrm{II})$ to $\mathrm{Fe}(\mathrm{III})$. Two key factors (and their interaction) 
that determine their unique properties are the "electronic coupling" between the two redox sites, and the "reorganization energy" associated with electron transfer between them. ${ }^{21}$ Charge localization or delocalization has been a central issue in mixed-valence chemistry. By a classification scheme proposed by Robin and Day, ${ }^{22}$ mixed-valent compounds can be completely localized, fully delocalized, or systems in between, depending on the strength of the electron interaction between the oxidized and reduced sites. To date, compounds of group 8-11 transition metals have been most intensively studied. In particular, compounds of iron, ruthenium, platinum, and copper have been widely studied. ${ }^{23}$ For example, many mixed-valent copper-based oxides have been developed as superconductors. The compound $\mathrm{YBa}_{2} \mathrm{Cu}_{3} \mathrm{O}_{7}$ has mixed-valent $\mathrm{Cu}$ (II) and $\mathrm{Cu}(\mathrm{III})$. Also, a number of rare-earth compounds with atomic-like $f$ levels coexisting with wide $s-d$ band at the Fermi level have shown very unique thermal and magnetic properties. $^{24}$

However, the nature of the mixed-valent chemistry on the surface of nanostructured materials has not yet been fully understood and a fundamental understanding of the relationship between mixed-valent structure and properties is still lacking. It should be also noted that the mixed-valence chemistry of the early transition metals is considerably less well established, yet a remarkable variety of structurally diverse mixed-valence compounds can be formed from these elements. Their wide range of oxidation states, coordination numbers, and geometries can offer great potential for the formation of unique mixed-valent compounds, and many of these may exhibit distinctive bonding, chemistry, and properties suitable for various applications. In particular, although early transition elements such as titanium, vanadium, and manganese are important in biology, catalysis, artificial photosynthesis, and energy storage/conversion science, the controlled synthesis of their mixed-valent compounds and their unique electrochemical properties have not yet been explored. In this paper, we demonstrated the controlled synthesis of nanostructured, mixed-valent manganese oxides and explored their unique properties as electrodes for high-performance pseudocapacitors.

We used conductive and porous carbon fiber paper (CFP) as both the current collector and the electrode for conformal coating of mixed- valence $\mathrm{MnO}_{x}$ as the active electrode material for pseudocapacitors (Figure 1a,b). Individual carbon fibers in the CFP are well-connected and the pores are sufficiently large to allow efficient ion access to all surface area of the electrode. We deposited a thin, uniform coating of nanoporous $\mathrm{MnO}_{x}$ directly onto porous CFP using a simple precipitation method in an aqueous solution at $75{ }^{\circ} \mathrm{C}$ (Figure $1 \mathrm{c}, \mathrm{d}$ ). The porous network structure of the CFP is retained because the conformal $\mathrm{MnO}_{x}$ coating is relatively thin, as revealed by microscopy. The $\mathrm{MnO}_{x}$ coated CFP were then heat-treated at $200-450{ }^{\circ} \mathrm{C}$ in different atmospheres (air, $\mathrm{N}_{2}$, and $4 \% \mathrm{H}_{2}$ ). TEM analysis of the samples annealed at $400{ }^{\circ} \mathrm{C}$ in air for $2 \mathrm{~h}$ revealed that the $\mathrm{MnO}_{x}$ films consist of many low aspect-ratio crystals (each being a few tens of nanometers in size) as well as clustered and needle-shaped crystals, whose diameters vary from a few nanometers to $\sim 10 \mathrm{~nm}$ (Figure $1 \mathrm{e}-\mathrm{g}$, Supporting Information S1). Selected area electron diffraction (SAED) analysis (Supporting Information Figure S1b) suggested that the lowaspect ratio nanocrystals examined are $\alpha-\mathrm{Mn}_{2} \mathrm{O}_{3}$ with a lattice constant of $0.94 \mathrm{~nm}$, and the needle-shaped crystals were identified as $\mathrm{Mn}_{3} \mathrm{O}_{4}$ (Hausmannite) based on lattice images (Figure 1g). The lattice fringes reveal the axes of the two needle-shaped $\mathrm{Mn}_{3} \mathrm{O}_{4}$ crystals are parallel to the (101) lattice planes (Supporting Information Figure S1c). Since both the (101) and (011) spacing are the largest lattice spacing in the $\mathrm{Mn}_{3} \mathrm{O}_{4}$ lattice, such an orientation may facilitate the incorporation and transport of ions along this direction. The thickness of $\mathrm{MnO}_{x}$ coating varied from $\sim 70$ to $\sim 800 \mathrm{~nm}$ (Supporting Information Figure S2-S4), depending on the deposition time ( 2 to $30 \mathrm{~min}$ ).

To further characterize the structural features of the $\mathrm{MnO}_{x}$ coatings formed on CFP, we used both laboratory and synchrotron-based X-ray diffraction (XRD) analysis. Figure 2a

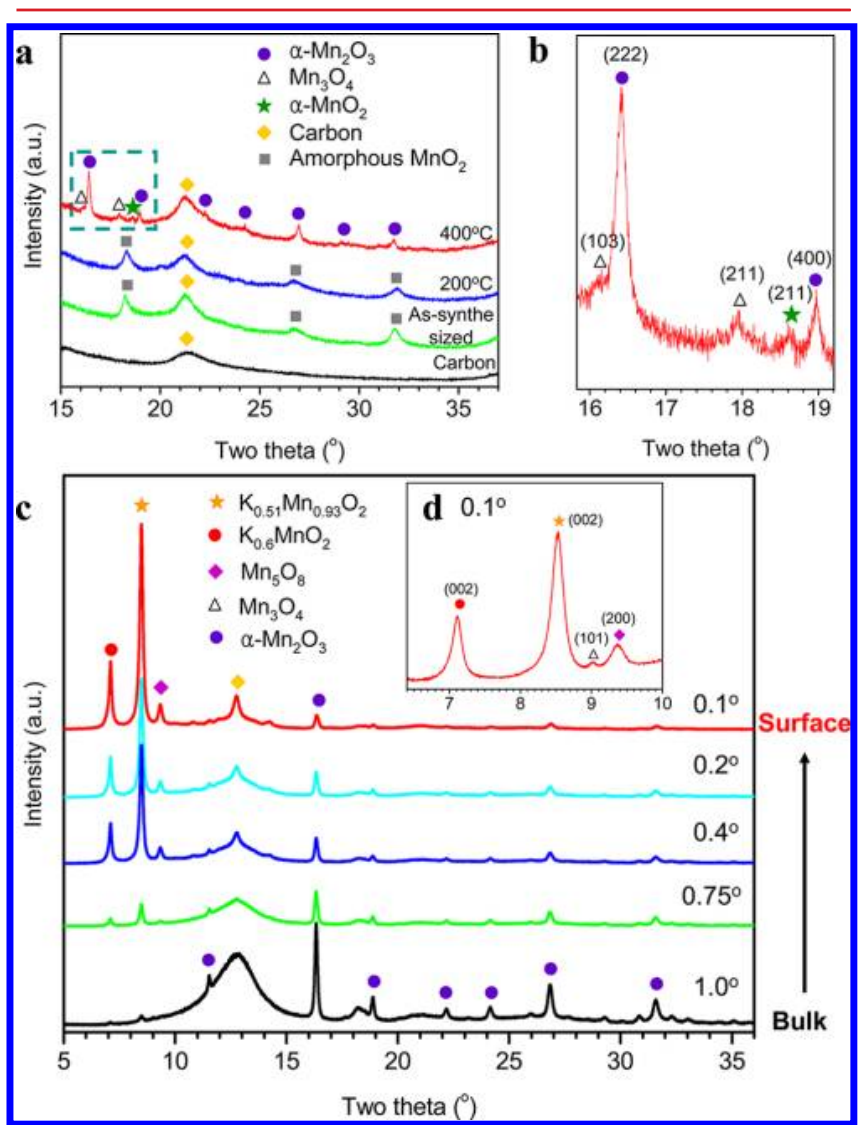

Figure 2. Synchrotron XRD analysis. (a) Transmission mode XRD pattern: bare carbon paper before coating, $\mathrm{MnO}_{x}$ electrodes before and after annealing at different temperatures $\left(200\right.$ and $\left.400{ }^{\circ} \mathrm{C}\right)$ in air for $2 \mathrm{~h}$. (b) Enlarged view of XRD pattern between $16-19^{\circ}$ of XRD pattern of $\mathrm{MnO}_{x}$ annealed at $400{ }^{\circ} \mathrm{C}$ in air for $2 \mathrm{~h}$ and highlighted in Figure 2a. (c) XRD pattern at of $\mathrm{MnO}_{x}$ annealed at $400{ }^{\circ} \mathrm{C}$ in air for 2 $\mathrm{h}$ measured at different incident angle $\left(0.1-1^{\circ}\right)$. (d) XRD pattern at incident glancing angle of $0.1^{\circ}$ of $\mathrm{MnO}_{x}$ annealed at $400{ }^{\circ} \mathrm{C}$ in air for 2 $\mathrm{h}$ showing the representative surface species.

shows the synchrotron-based XRD patterns (transmission mode) of samples (deposited for $30 \mathrm{~min}$ ) before and after annealing in air at different temperatures. The very broad characteristic peaks in the XRD patterns indicated that the asdeposited $\mathrm{MnO}_{2}$ coating was amorphous and remained so after annealing at $200{ }^{\circ} \mathrm{C}$ in air for $2 \mathrm{~h}$, which is consistent with previous studies under similar synthesis conditions. ${ }^{25,26}$ The amorphous phase of $\mathrm{MnO}_{2}$ was believed to be good electrode materials for pseudocapacitors. ${ }^{7,26,27}$ When annealed with CFP at $400{ }^{\circ} \mathrm{C}$ in air for $2 \mathrm{~h}$, the amorphous $\mathrm{MnO}_{2}$ was converted to crystalline $\alpha-\mathrm{Mn}_{2} \mathrm{O}_{3}$ with small amount of $\mathrm{Mn}_{3} \mathrm{O}_{4}$ (Hausmannite) and $\alpha-\mathrm{MnO}_{2}$, as evident from the XRD patterns shown in 

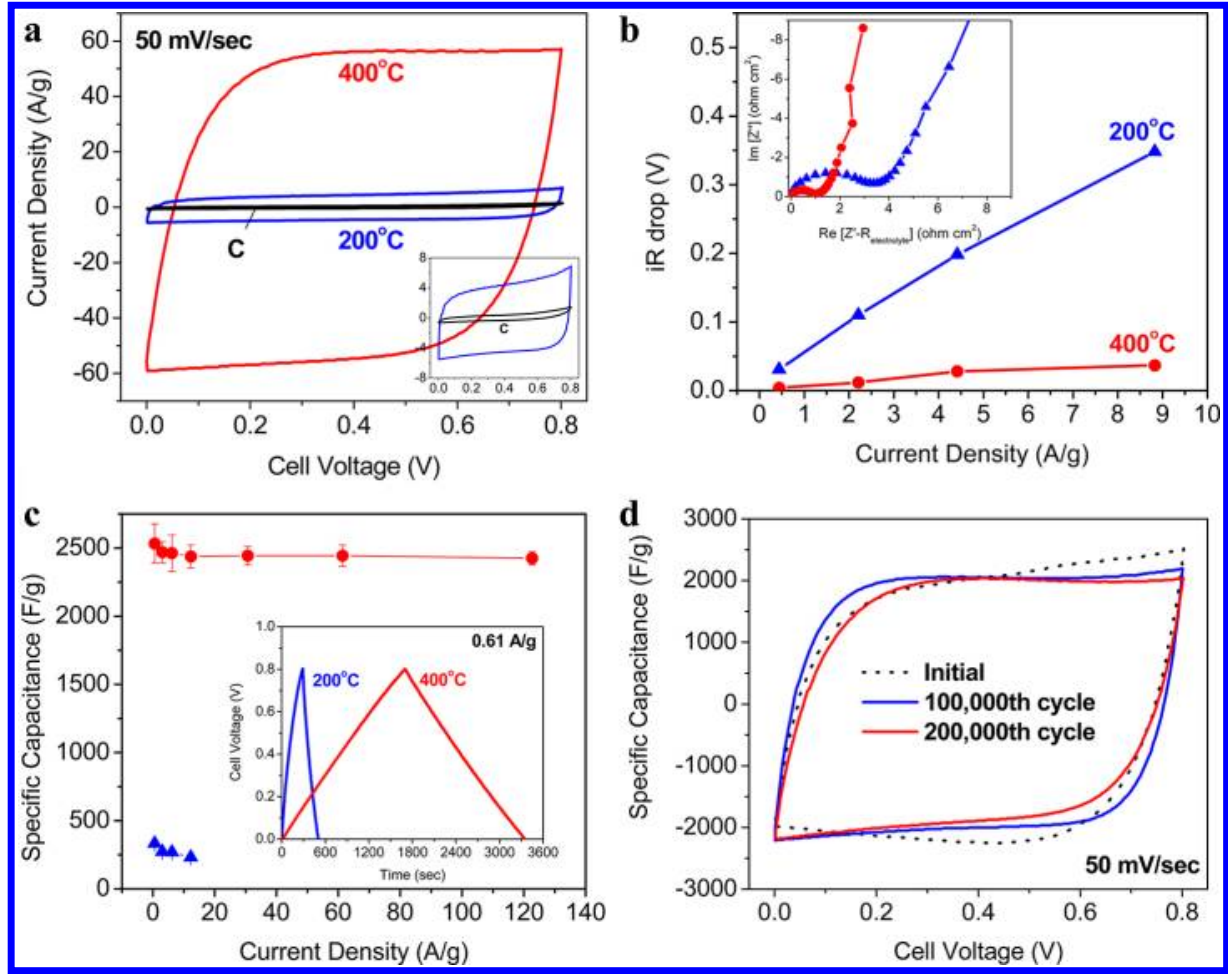

Figure 3. Electrochemical performance of symmetric pseudocapacitors constructed from amorphous $\mathrm{MnO}_{2}$ and mixed-valent $\mathrm{MnO}_{\mathrm{x}}$ electrodes. (a) Cyclic voltammograms measured between $0-0.8 \mathrm{~V}$ at a scan rate of $50 \mathrm{mV} / \mathrm{s}$. (b) $i R$ drop of the cells measured at different current densities. Insert shows electrochemical impedance spectra collected at open circuit voltage under the influence of an ac voltage of $10 \mathrm{mV}$. (c) Specific capacitance at different current densities demonstrating superior rate-capability. Insert shows typical charge-discharge curves of amorphous $\mathrm{MnO}_{2}$ and mixedvalent $\mathrm{MnO}_{x}$ electrodes at a constant current density of $0.61 \mathrm{~A} / \mathrm{g}$. Only the weight of the active electrode material $(\mathrm{MnO}, \sim 0.32 \mathrm{mg})$ was considered in the specific capacitance calculations. (d) Cyclic voltammograms before and after long-term cycling at a scan rate of $50 \mathrm{mV} / \mathrm{s}$ showing excellent cycling stability.

Figure 2a,b. These crystalline phases started to appear at $\sim 360$ ${ }^{\circ} \mathrm{C}$ when the temperature was raised from 200 to $400{ }^{\circ} \mathrm{C}$ in air, as revealed by the in situ XRD analysis (Supporting Information Figure S5). It is noted, however, that the transmission-mode XRD pattern is quite different from those collected at a small glancing angle (Supporting Information Figure S6), suggesting that the phases on the surface are very different from those in the bulk.

To gain some insights into the structures of the surface layer, we collected XRD patterns at different glancing incident angles (Figure 2c,d). A lower incident angle corresponds to a shallower penetration depth of the X-ray, allowing us to probe the structure of a layer closer to the surface. When the incident angle was varied from 1 to $0.1^{\circ}$, the $\alpha-\mathrm{Mn}_{2} \mathrm{O}_{3}$ peaks decreased gradually while the peaks corresponding to $\mathrm{K}$ incorporated $\mathrm{MnO}_{2}\left(\mathrm{~K}_{0.6} \mathrm{MnO}_{2}\right.$ and $\left.\mathrm{K}_{0.51} \mathrm{Mn}_{0.93} \mathrm{O}_{2}\right)$ and $\mathrm{Mn}_{5} \mathrm{O}_{8}$ increased considerably, suggesting that $\alpha-\mathrm{Mn}_{2} \mathrm{O}_{3}$ is present predominantly in the bulk whereas the K-incorporated $\mathrm{MnO}_{2}$ and $\mathrm{Mn}_{5} \mathrm{O}_{8}$ are formed mostly near the surface (Figure $2 \mathrm{~d}$ ). It is noted that small peaks corresponding to $\mathrm{Mn}_{3} \mathrm{O}_{4}$ were observable in both transmission-mode and glancing angle mode XRD patterns, implying that small amount of $\mathrm{Mn}_{3} \mathrm{O}_{4}$ is present in the bulk and on the surface. This is consistent with TEM observation (Figure $1 \mathrm{~g}$ ). The surface phases (K-incorporated $\mathrm{MnO}_{2}, \mathrm{Mn}_{5} \mathrm{O}_{8}$, and $\mathrm{Mn}_{3} \mathrm{O}_{4}$, ) were formed at $400{ }^{\circ} \mathrm{C}$, as indicated by the low glancing angle XRD analysis at different temperatures (Supporting Information Figure S7).

XRD analysis of the mixed-valent $\mathrm{MnO}_{x}$ of different thicknesses suggests that the predominating phase of the $\sim 800 \mathrm{~nm}$ films (deposited for $30 \mathrm{~min}$ ) was $\alpha-\mathrm{Mn}_{2} \mathrm{O}_{3}$ whereas that of the $\sim 70 \mathrm{~nm}$ films (deposited for $2 \mathrm{~min}$ ) was $\mathrm{Mn}_{3} \mathrm{O}_{4}$, which showed the highest specific capacitance. As the thickness was reduced (Supporting Information Figure S8), the predominating "bulk" phase was changed from $\alpha-\mathrm{Mn}_{2} \mathrm{O}_{3}$ to a phase similar to $\mathrm{Mn}_{3} \mathrm{O}_{4}$. This is anticipated because the degree of $\mathrm{MnO}_{x}$ reduction (by the carbon substrate) decreases in the direction away from the carbon substrate surface, which was exposed to air. The annealing condition created a gradient in oxidation state of $\mathrm{Mn}$ ion along the thickness direction; thinner $\mathrm{MnO}_{x}$ films deposited on carbon fiber were more reduced. However, they were still mixed-valent $\mathrm{MnO}_{x}$ and there is more $\mathrm{Mn}_{3} \mathrm{O}_{4}$ phase in a thinner film (Supporting Information Figure S8-S10). It is noted that all electrodes deposited for $2,5,15$, and $30 \mathrm{~min}$ have the same surface phases; the graded oxidation state remained largely the same.

Gas adsorption/desorption analysis implied that the microstructure of $\mathrm{MnO}_{x}$ underwent a dramatic rearrangement during the annealing process, producing porous, nanostructured $\mathrm{MnO}_{x}$ (Supporting Information Figure S11). The specific surface area increased from $5.21 \mathrm{~m}^{2} / \mathrm{g}$ for amorphous $\mathrm{MnO}_{2}$ to $261.8 \mathrm{~m}^{2} / \mathrm{g}$ for the multivalent $\mathrm{MnO}_{\mathrm{x}}$ as the pore volume increased from 0.021 to $0.149 \mathrm{~cm}^{3} / \mathrm{g}(\sim 42 \%$ porosity $)$ at the same time. The formation of tunneled structure of K-incorporated $\mathrm{MnO}_{2}$ on the surface may partially account for enlarged surface area and pore volume. ${ }^{18,28}$ The porous, nanostructured multivalent $\mathrm{MnO}_{x}$ is ideally suited for fast mass and charge transfer associated with energy storage processes.

To evaluate the characteristic behavior of the mixed-valent $\mathrm{MnO}_{x}$ electrodes for electrical energy storage, we performed several electrochemical measurements in a $1 \mathrm{M} \mathrm{Na}_{2} \mathrm{SO}_{4}$ 
solution. The mixed-valent $\mathrm{MnO}_{x}$ electrode showed excellent "square-shape" cyclic voltammograms at $50 \mathrm{mV} / \mathrm{s}$ (Figure 3a) with current densities being almost 1 order of magnitude higher than those of the amorphous $\mathrm{MnO}_{2}$ electrode. The symmetric shape and the instant response upon the reversal of voltage indicate that surface reactions are highly reversible and very fast. It is noted that the contribution of the porous carbon fiber substrate to the capacitance is negligible.

We have also measured the internal resistance of the electrochemical capacitors when the potentials were reversed (Supporting Information Figure S12) and plotted them as a function of applied current densities (Figure 3b). The slopes of the plots correspond directly to the equivalent series resistances (ESR) of the capacitors. This internal resistance critically influences the power density (or rate capability) of electrochemical capacitors; low capacitance and deviation from ideal capacitor behavior are usually associated with large ESR. It is clearly shown that the mixed-valent $\mathrm{MnO}_{x}$ displayed much smaller ESR than the amorphous $\mathrm{MnO}_{2}$ at a given current density due most likely to enhanced rates of the surface redox reactions. This observation was further confirmed by the impedance measurements (insert of Figure $3 b$ ). The chargetransfer resistance (the diameter of the semicircle in the impedance spectrum) of the mixed-valent $\mathrm{MnO}_{x}$ was much smaller than that of the amorphous $\mathrm{MnO}_{2}$. The long tail at low frequencies of the mixed-valent $\mathrm{MnO}_{x}$ is closer to a vertical line for an ideal capacitor, another indication that the mixed-valent $\mathrm{MnO}_{x}$ has higher capacitance and lower resistance than the amorphous $\mathrm{MnO}_{2}$.

Typical charge-discharge curves at a constant current of 0.61 $\mathrm{A} / \mathrm{g}$ are shown in Figure 3c. The "linear" and symmetrical charge-discharge curves indicate again high Coulombic efficiency or excellent reversibility. The specific capacitance (calculated from the discharge curve) of the amorphous $\mathrm{MnO}_{2}$ was $333 \mathrm{~F} / \mathrm{g}$, comparable to the values reported in the literatures. $^{26,29}$ In contrast, the specific capacitance for the mixed-valent $\mathrm{MnO}_{x}$ (of $\sim 70 \mathrm{~nm}$ thick) was $\sim 2530 \mathrm{~F} / \mathrm{g}$, almost eight times higher than that of the amorphous $\mathrm{MnO}_{2}$ (of the same loading). This represents the highest specific capacitance ever reported among all known pseudocapacitor materials, including $\mathrm{MnO}_{2}(1145 \mathrm{~F} / \mathrm{g}$; film $<40 \mathrm{~nm}$ thick in a $100 \mathrm{~nm}$ porous $\mathrm{Au}$ film $),{ }^{17} \mathrm{Ni}(\mathrm{OH})_{2}(1335 \mathrm{~F} / \mathrm{g}$; nanoplates $<10 \mathrm{~nm}$ thick), ${ }^{30}$ and $\mathrm{RuO}_{2}(1340 \mathrm{~F} / \mathrm{g}$; nanodots with $2-3 \mathrm{~nm}$ in diameter $)^{31}$ when all normalized to the weight of the active material only.

Because high rate capability is the most important feature of electrochemical capacitors, we measured the performance at very high cycling rates. Typically, the capacitance of a pseudocapacitor may decrease with operating current density due to mass transport limitations, especially when insertion (or removal) of ions into (or from) the electrode subsurface is involved. Much to our surprise, however, the capacitance of the mixed-valent $\mathrm{MnO}_{x}$ was not kinetically limited even at very high cycling rates (Supporting Information Figure S13), demonstrating $\sim 2430 \mathrm{~F} / \mathrm{g}$ at $122.7 \mathrm{~A} / \mathrm{g}$. Further, the mixedvalent $\mathrm{MnO}_{x}$ electrode displayed remarkable long-term cycling stability; cyclic voltammograms collected after 100000 and 200 000 cycles (Figure 3d) showed little change, whereas the capacitance of the amorphous $\mathrm{MnO}_{2}$ was much lower and degraded considerably during cycling (Supporting Information Figure S14-15). It was also found that symmetric pseudocapacitors constructed from the mixed-valent $\mathrm{MnO}_{x}$ showed very stable performance up to $1.0 \mathrm{~V}$ (Supporting Information Figure S16).

It is noted, however, that the specific capacitance drops with the thickness of the $\mathrm{MnO}_{x}$ film (or loading), suggesting that only a thin film was fully utilized (or the nanoporous surface phases make dominating contributions to the observed capacitance) (Supporting Information Figure S17-18). This is not surprising because the charge storage in a capacitor is primarily confined to the surface and subsurface (or a thin layer). To increase the performance of electrochemical capacitors by increasing the film thickness of active materials is proven ineffective and, perhaps, fundamentally unattainable; after all, the rate capability may ultimately diminish with film thickness. However, our results demonstrate that it may be unnecessary to increase film thickness because the charge storage capacity of the $\mathrm{MnO}_{x}$ film can be dramatically enhanced ( $\sim 8$ times $)$ by creating mixed-valent nanostructure, achieving values much higher than the "theoretical capacity" previously believed (e.g., $\sim 1370 \mathrm{~F} / \mathrm{g}$ for $\mathrm{MnO}_{2}$ under similar conditions). ${ }^{8}$ Indeed, the estimated specific energy density of the $\sim 70 \mathrm{~nm}$ thick mixed-valent $\mathrm{MnO}_{x}$ film (single electrode in a voltage window between 0 and $1.0 \mathrm{~V}$ ) reached $\sim 352 \mathrm{Wh} / \mathrm{kg}$ at a power density of $\sim 614 \mathrm{~W} / \mathrm{kg}$ and showed little dependence on cycling rate, still retaining $\sim 337 \mathrm{Wh} / \mathrm{kg}$ at power densities up to $\sim 117$ $800 \mathrm{~W} / \mathrm{kg}$ (full charge or discharge in $10 \mathrm{~s}$ ) when all normalized to the weight of active material only. The demonstrated specific energy densities of single electrode are much higher than those of the state-of-art pseudocapacitor materials $^{17,30}$ (Note the voltage window for $\mathrm{MnO}_{2}$ and $\mathrm{Ni}(\mathrm{OH})_{2}$ were 0.8 and $0.55 \mathrm{~V}$ in two- and three-electrode configuration, respectively) and even comparable to those of high-performance battery materials such as $\mathrm{FePO}_{4}$ nanowires $(\sim 300 \mathrm{Wh} / \mathrm{kg}$ at $\sim 4000 \mathrm{~W} / \mathrm{kg})$ and $\mathrm{Li}\left(\mathrm{Ni}_{0.5} \mathrm{Mn}_{0.5}\right) \mathrm{O}_{2}(\sim 600$ $\mathrm{Wh} / \mathrm{kg}$ at $\sim 6000 \mathrm{~W} / \mathrm{kg}$ ) while retaining much higher gravimetric power (when all normalized to the weight of the electrode material only). ${ }^{32,33}$ Although significantly improved performance has been achieved in this study with a nanoscale coating, the mixed-valent $\mathrm{MnO}_{x}$ shows great potential to provide an order of magnitude increase in practical energy density of electrochemical capacitors without penalizing power density. We believe that $\mathrm{MnO}_{x}$ coatings must be thin to offer the best possible power density. Therefore, one effective approach to increasing practical energy density (e.g., loading) without compromising the specific capacitance or rate capability is to use nanocarbon fibers, thus increasing the surface area of CFP for conformal coating of $\mathrm{MnO}_{x}$.

The phase composition and nanostructure of the electrode material is very sensitive to the annealing conditions. For example, when the annealing temperature was increased from 400 to $450{ }^{\circ} \mathrm{C}$ (but still in air for $2 \mathrm{~h}$ ), XRD analysis suggested that the $\mathrm{Mn}_{3} \mathrm{O}_{4}$ phase was converted to $\alpha-\mathrm{Mn}_{2} \mathrm{O}_{3}$ (Supporting Information Figure S19). Similarly, when the annealing atmosphere was changed from air to $\mathrm{N}_{2}$ and $4 \% \mathrm{H}_{2}$ balanced with $\mathrm{Ar}$ (still at $400{ }^{\circ} \mathrm{C}$ for $2 \mathrm{~h}$ ), the as-synthesized amorphous $\mathrm{MnO}_{2}$ on CFP was converted to pure $\mathrm{Mn}_{3} \mathrm{O}_{4}$ and a mixture of $\mathrm{MnO}$ and $\mathrm{Mn}_{3} \mathrm{O}_{4}$, respectively (Supporting Information Figure S20). Further, the amorphous $\mathrm{MnO}_{2}$ powder sample (synthesized under the same conditions but without carbon support) remained amorphous when annealed at $400{ }^{\circ} \mathrm{C}$, but transformed to crystalline $\alpha-\mathrm{Mn}_{2} \mathrm{O}_{3}$ when annealed at $500{ }^{\circ} \mathrm{C}$, in air for $2 \mathrm{~h}$ in the absence of carbon (Supporting Information Figure S21). Electrodes made of these phases performed poorly, far inferior to that of the electrodes made of the 


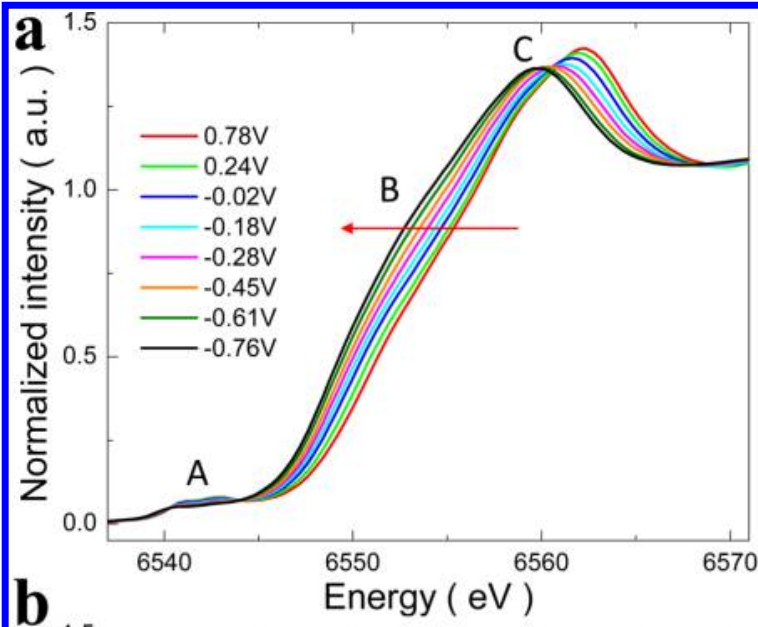

c
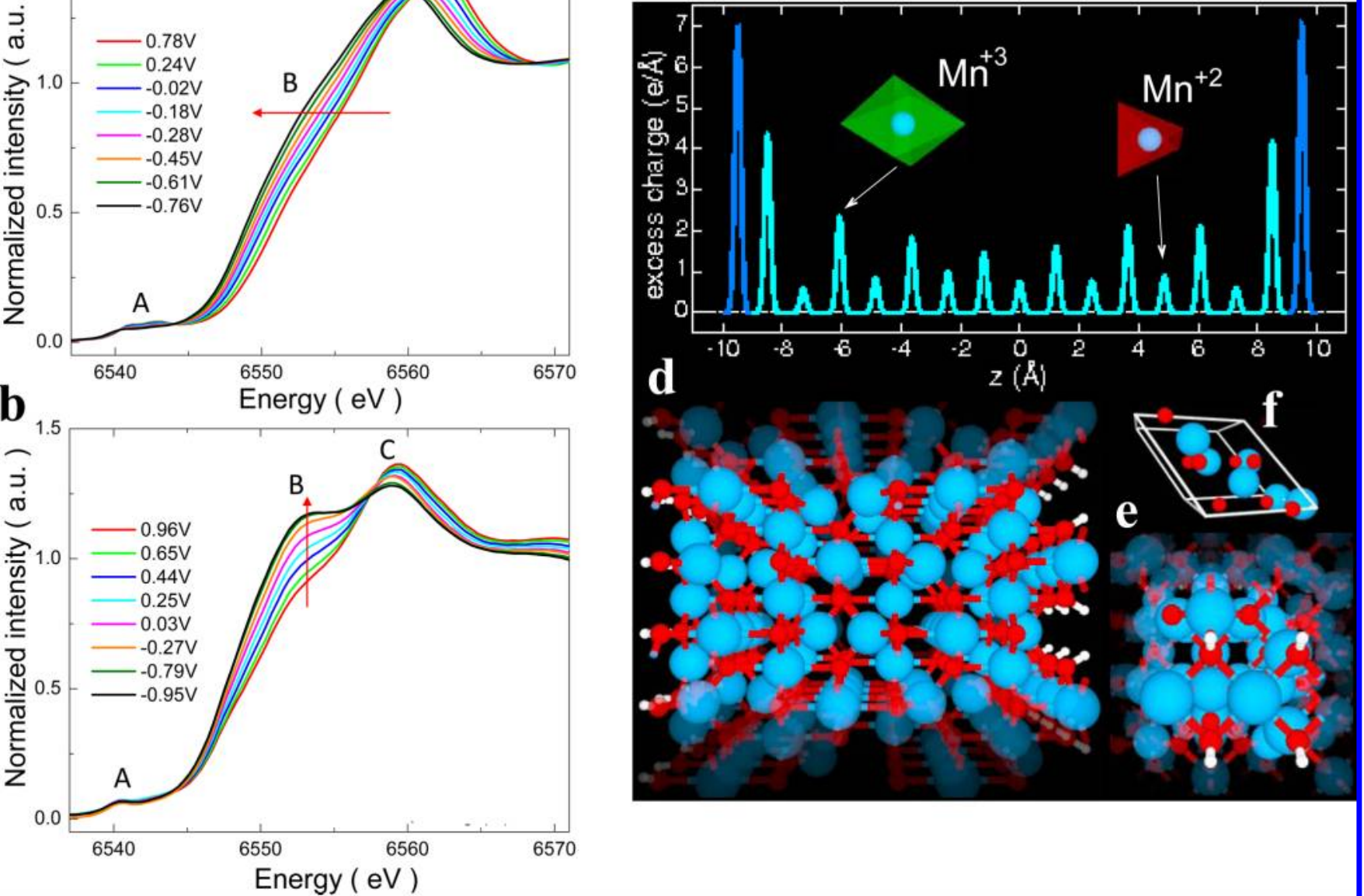

Figure 4. Investigation into the charge storage mechanism. (a) In situ XANES spectra of the as-synthesized (amorphous $\mathrm{MnO}_{2}$ ) and $(\mathrm{b})$ the mixedvalent $\mathrm{MnO}_{\mathrm{x}}$ electrode during discharge in $1.0 \mathrm{M} \mathrm{Na}_{2} \mathrm{SO}_{4}$ electrolyte. $\mathrm{A}, \mathrm{B}$, and $\mathrm{C}$ represent pre-edge (1s $\rightarrow 3 \mathrm{~d}$ transition), covalent character between $\mathrm{Mn}(3 \mathrm{~d})$ and $\mathrm{O}(2 \mathrm{p})$ bond due to LMCT, and main edges ( $1 \mathrm{~s} \rightarrow 4 \mathrm{p}$ transition). (c) Linear excess charge distribution across the slab of $\mathrm{Mn}_{3} \mathrm{O}_{4}$ as derived from $\mathrm{PBE}+\mathrm{U}$ calculations. The distribution is normalized to the number of excess electrons added to the slab model. The charge accumulated at the surface is shown in blue, while the cyan color is used to show the charge distribution in the bulk stored in the $\left[\mathrm{MnO}_{4}\right]$ tetrahedra and $\left[\mathrm{MnO}_{6}\right]$ octahedra, respectively. (d) Side view and (e) top view of the slab used in the PBE+U calculations. (f) Primitive unit cell of $\mathrm{Mn}_{3} \mathrm{O}_{4}$. $\mathrm{Mn}$ and $\mathrm{O}$ atoms are shown in blue and red colors, respectively.

multivalent $\mathrm{MnO}_{x}$ created by annealing in air at $400{ }^{\circ} \mathrm{C}$ for $2 \mathrm{~h}$ (Supporting Information Figure S19-S20).

Since the mixed-valent phases seem to play a pivotal role in achieving the anomalously high capacitance, we performed both ex situ and in situ XAS to gain some insights into the chargestorage mechanism of the mixed-valent $\mathrm{MnO}_{x}$ electrodes (Supporting Information Figure S22-S23). The in situ X-ray absorption near edge spectroscopy (XANES) spectra (Figure 4a) for the as-synthesized $\mathrm{MnO}_{2}$ electrodes acquired during the first discharge $(0.8$ to $-0.8 \mathrm{~V})$ showed an entire edge shift toward lower energy in a continuous manner, suggesting that the charge storage is mostly associated with the $\mathrm{Mn}^{3+} / \mathrm{Mn}^{4+}$ redox reactions, as conventionally believed. In contrast, however, the XANES spectra (Figure $4 \mathrm{~b}$ ) for the mixed-valent $\mathrm{MnO}_{x}$ collected under the identical conditions (except over a wider voltage window from 1.0 to $-1.0 \mathrm{~V}$ ) showed completely different spectral features that have never before been reported. First, there was no obvious entire edge shift during discharge, although a slight edge shift toward lower energy was observed, indicating a decrease in average oxidation state of $\mathrm{Mn}$ ions. The average change in $\mathrm{Mn}$ valence (calculated from the edge shift) for both cases was similar: $\sim 0.3$ within a voltage window of 0.0 to $0.8 \mathrm{~V}$ (Supporting Information Figure S23); yet, the observed specific capacitance for the mixed-valent $\mathrm{MnO}_{x}$ is much higher ( $\sim 8$ times) than that for the as-prepared $\mathrm{MnO}_{2}$ sample. Clearly, the change in oxidation state of $\mathrm{Mn}$ ion cannot account for the anomalous pseudocapacitive behavior. Second, the dominating spectral feature is a unique evolution of the shoulder peak (B), which is related to the ligand-to-metal charge transfer (LMCT) process. The increased B peak intensity indicates the increased degree of covalent character of $\mathrm{Mn}(3 \mathrm{~d})-\mathrm{O}(2 \mathrm{p})$ bonding during the discharge. Thus, the unique $\mathrm{Mn} \mathrm{K}$-edge change in the form of increasing B feature clearly shows that a large portion of the charge compensation might be originated from the hole state redistribution toward the oxygen sites, rather than just the reduction of $\mathrm{Mn}$ ion (as seen for the as-synthesized $\mathrm{MnO}_{2}$ ), suggesting that the unique atomic and electronic structure (Supporting Information Figure S22) of the nanostructured, mixed-valent $\mathrm{MnO}_{x}$ may allow additional charge compensation mechanism, which has not been observed in $\mathrm{MnO}_{2}$. Although small intensity change of $\mathrm{B}$ feature in XANES spectra during charge-discharge were reported in the literature ${ }^{34,35}$ for transition metal K-edges such as $\mathrm{Co}$ and $\mathrm{Mn}$, it has never before been observed that 
these spectral changes (LMCT) play a dominating role over the continuous edge shift (redox reaction of cations).

The role of oxygen anions for charge compensation in transition metal oxides is not unprecedented; it was previously argued for lithium battery electrodes. Aydinol et al. showed that more charge can be transferred to the oxygen anions than to the metal cations in the oxide upon intercalation of lithium ions. ${ }^{36}$ To estimate the charge distribution in the nanoporous multivalent $\mathrm{MnO}_{x}$ (with dominant phase of $\mathrm{Mn}_{3} \mathrm{O}_{4}$ ), we resorted to spin-polarized density functional theory (DFT) calculations. To model the geometry of $\mathrm{Mn}_{3} \mathrm{O}_{4}$ nanoneedles (as seen in Figure $1 \mathrm{~g}$ ), we used a tetragonal slab of $\mathrm{Mn}_{3} \mathrm{O}_{4}$ exposing to the vacuum two opposite (001) surfaces of area $5.94 \times 5.94 \AA^{2}$ and having a linear dimension perpendicular to the surface of $19.5 \AA$. Our DFT calculations (Figure 4c) show that significant amount of the excess negative charge is indeed accumulated at the surface of the $\mathrm{Mn}_{3} \mathrm{O}_{4}$ nanoneedles. In the bulk, the excess negative charge gradually decays from the surface peak, localizing prevalently in correspondence of the $\mathrm{Mn}^{3+}$ ions in the $\left[\mathrm{MnO}_{6}\right]$ octahedra rather than at the $\mathrm{Mn}^{2+}$ centers in the $\left[\mathrm{MnO}_{4}\right]$ tetrahedra. An analysis of the individual Bader atomic charges ${ }^{37}$ shows, in particular, that the percentage of excess charge stored at the surface and in the bulk of $\mathrm{Mn}_{3} \mathrm{O}_{4}$ is 36 and $64 \%$, respectively, while in the bulk the negative charge accumulated at or in proximity of $\mathrm{Mn}^{2+}, \mathrm{Mn}^{3+}$, and $\mathrm{O}$ centers is 15,50 , and $35 \%$, respectively.

Our DFT calculations therefore suggest that the amounts of excess charge accumulated on the surface and at $\mathrm{O}$ centers are significant, consistent with our in situ XAS results. Charge accumulation on $\mathrm{O}$ centers appear to be favored by the close proximity of the $\mathrm{Mn}^{3+}$ species that, thanks to the good hybridization of the $\mathrm{Mn}^{3+} 3 \mathrm{~d}$ and the $\mathrm{O} 2 \mathrm{p}$ orbitals, spill the excess negative charge onto the neighboring $\mathrm{O}$ atoms. These new charge compensation mechanisms at $\mathrm{O}$ centers and surfaces directly challenge the traditional notion that pseudocapacitance is primarily associated with redox reaction of cations.

Additionally, the coexistence of aliovalent cations $\left(\mathrm{Mn}^{2+}\right.$, $\mathrm{Mn}^{3+}$, and $\mathrm{Mn}^{4+}$ ) may facilitate the formation of more ionic defects (e.g., vacancies and misplaced ions) and electronic defects (electrons and holes), thus altering the electronic, ionic, and catalytic properties of the manganese oxides. These defects may accelerate the kinetics of the surface redox reactions. Also, the mismatches induced by structural differences among different manganese oxide phases may produce additional defects (cavities, stacking faults, etc.), thus facilitating the formation of porous nanoarchitectures that may enhance the transport of charged species and extend the reaction sites from the surface to the subsurface of electrode. Recent theoretical studies predicted that photoconductivity of $\mathrm{MnO}_{2}$ can be enhanced by introducing Ruetschi defects or protonated $\mathrm{Mn}$ (IV) vacancies, suggesting that electronic properties can be tailored by tuning the defect structure during synthesis. ${ }^{38}$

Our results suggest that electrochemical capacitors based on this $\mathrm{MnO}_{x}$ film have potential to reach energy densities much higher than those of existing pseudocapacitors while maintaining high rate capabilities and excellent cycling performance of EDLCs. This can be accomplished by the creation of thin films of mixed-valent manganese oxides with porous nanoarchitecture, enabling multiple charge storage mechanisms with much smaller internal resistance and highly reversible, faster charge transfer kinetics. Although we have focused on $\mathrm{MnO}_{x}$ as active materials for pseudocapacitors in this study, other transition metal oxides could also be explored using a similar method to design mixed-valent nanostructures/carbon composites with significantly enhanced electrochemical performances for other applications.

\section{ASSOCIATED CONTENT}

\section{Supporting Information}

Additional figures and experimental details are included. This material is available free of charge via the Internet at http:// pubs.acs.org.

\section{AUTHOR INFORMATION}

\section{Corresponding Author}

*E-mail: meilin.liu@mse.gatech.edu.

\section{Author Contributions}

\#These authors contributed equally to this work.

\section{Notes}

The authors declare no competing financial interest.

\section{ACKNOWLEDGMENTS}

This material is based upon work supported as part of the HeteroFoaM Center, an Energy Frontier Research Center funded by the U.S. Department of Energy (DOE), Office of Science, Office of Basic Energy Sciences (BES) under Award Number DE-SC0001061. The authors acknowledge the use of the X14A beamline at Brookhaven National Laboratory (BNL, partially sponsored by the U.S.-DOE-EERE, Vehicle Technologies Program, through the HTML User Program at ORNL) and the SHaRE User Facility at Oak Ridge National Laboratory (ORNL, sponsored by the Scientific User Facilities Division, US-DOE-BES). K.W.N. and X.Q.Y. are supported by the U.S.-DOE Assistant Secretary for EERE, Office of Vehicle Technologies, Vehicle Technology Program, under Contract Number DEAC02-98CH10886. Partial support of the WCU program at UNIST is also acknowledged. M.K.S. and S.C. thank K. Blinn, S. Lai, and M. F. Liu for their help on Raman spectroscopy and TGA measurements.

\section{REFERENCES}

(1) Whittingham, M. S. MRS Bull. 2008, 33 (4), 411-419.

(2) Conway, B. E. Electrochemical Supercapacitors; Kluwer-Academic: New York, 1999.

(3) Chmiola, J.; Yushin, G.; Gogotsi, Y.; Portet, C.; Simon, P.; Taberna, P. L. Science 2006, 313 (5794), 1760-1763.

(4) Simon, P.; Gogotsi, Y. Nat. Mater. 2008, 7 (11), 845-854.

(5) Hall, P. J.; Mirzaeian, M.; Fletcher, S. I.; Sillars, F. B.; Rennie, A. J. R.; Shitta-Bey, G. O.; Wilson, G.; Cruden, A.; Carter, R. Energy Environ. Sci. 2010, 3 (9), 1238-1251.

(6) Brezesinski, T.; Wang, J.; Tolbert, S. H.; Dunn, B. Nat. Mater. 2010, 9 (2), 146-151.

(7) Lee, H. Y.; Goodenough, J. B. J. Solid State Chem. 1999, 144 (1), 220-223.

(8) Toupin, M.; Brousse, T.; Belanger, D. Chem. Mater. 2004, 16 (16), 3184-3190.

(9) Yu, G.; Hu, L.; Liu, N.; Wang, H.; Vosgueritchian, M.; Yang, Y.; Cui, Y.; Bao, Z. Nano Lett. 2011, 11 (10), 4438-4442.

(10) $\mathrm{Yu}, \mathrm{G} . ; \mathrm{Hu}, \mathrm{L} . ;$ Vosgueritchian, M.; Wang, H.; Xie, X.; McDonough, J. R.; Cui, X.; Cui, Y.; Bao, Z. Nano Lett. 2011, 11 (7), 2905-2911.

(11) Hu, L.; Pasta, M.; Mantia, F. L.; Cui, L.; Jeong, S.; Deshazer, H. D.; Choi, J. W.; Han, S. M.; Cui, Y. Nano Lett. 2010, 10 (2), 708-714.

(12) Raymundo-Pinero, E.; Khomenko, V.; Frackowiak, E.; Beguin, F. J. Electrochem. Soc. 2005, 152 (1), A229-A235. 
(13) Chou, S. L.; Wang, J. Z.; Chew, S. Y.; Liu, H. K.; Dou, S. X. Electrochem. Commun. 2008, 10 (11), 1724-1727.

(14) Fischer, A. E.; Pettigrew, K. A.; Rolison, D. R.; Stroud, R. M.;

Long, J. W. Nano Lett. 2007, 7 (2), 281-286.

(15) Lee, S. W.; Kim, J.; Chen, S.; Hammond, P. T.; Shao-Horn, Y. ACS Nano 2010, 4 (7), 3889-3896.

(16) Chen, S.; Zhu, J.; Wu, X.; Han, Q.; Wang, X. ACS Nano 2010, 4 (5), 2822-2830.

(17) Lang, X. Y.; Hirata, A.; Fujita, T.; Chen, M. W. Nat. Nanotechnol. 2011, 6 (4), 232-236.

(18) Post, J. E. Proc. Natl. Acad. Sci. U.S.A. 1999, 96 (7), 3447-3454.

(19) Shen, Y. F.; Zerger, R. P.; Deguzman, R. N.; Suib, S. L.;

McCurdy, L.; Potter, D. I.; Oyoung, C. L. Science 1993, 260 (5107),

$511-515$.

(20) Tian, Z. R.; Tong, W.; Wang, J. Y.; Duan, N. G.; Krishnan, V. V.; Suib, S. L. Science 1997, 276 (5314), 926-930.

(21) Hankache, J.; Wenger, O. S. Chem. Rev. 2011, 111 (8), 51385178

(22) Robin, M. B.; Day, P. Mixed Valence Chemistry-A Survey and Classification. In Advances in Inorganic Chemistry; Emeléus, H. J.; Sharpe, A. G., Eds.; Academic Press: New York, 1968; Vol. 10, pp $247-422$.

(23) Young, C. G. Coord. Chem. Rev. 1989, 96, 89-251.

(24) Varma, C. M. Rev. Mod. Phys. 1976, 48 (2), 219-238.

(25) Ragupathy, P.; Park, D. H.; Campet, G.; Vasan, H. N.; Hwang, S. J.; Choy, J. H.; Munichandraiah, N. J. Phys. Chem. C 2009, 113 (15), 6303-6309.

(26) Xu, M. W.; Zhao, D. D.; Bao, S. J.; Li, H. L. J. Solid State Electrochem. 2007, 11 (8), 1101-1107.

(27) Subramanian, V.; Zhu, H. W.; Wei, B. Q. Electrochem. Commun. 2006, 8 (5), 827-832.

(28) Gao, T.; Glerup, M.; Krumeich, F.; Nesper, R.; Fjellvag, H.; Norby, P. J. Phys. Chem. C 2008, 112 (34), 13134-13140.

(29) Hu, C. C.; Tsou, T. W. Electrochem. Commun. 2002, 4 (2), 105109.

(30) Wang, H.; Casalongue, H. S.; Liang, Y.; Dai, H. J. Am. Chem. Soc. 2010, 132 (21), 7472-7477.

(31) Hu, C. C.; Chen, W. C.; Chang, K. H. J. Electrochem. Soc. 2004, 151 (2), A281-A290.

(32) Lee, Y. J.; Yi, H.; Kim, W. J.; Kang, K.; Yun, D. S.; Strano, M. S.; Ceder, G.; Belcher, A. M. Science 2009, 324 (5930), 1051-1055.

(33) Kang, K. S.; Meng, Y. S.; Breger, J.; Grey, C. P.; Ceder, G. Science 2006, 311 (5763), 977-980.

(34) Yoon, W. S.; Balasubramanian, M.; Chung, K. Y.; Yang, X. Q.; McBreen, J.; Grey, C. P.; Fischer, D. A. J. Am. Chem. Soc. 2005, 127 (49), 17479-17487.

(35) Kim, M. G.; Shin, H. J.; Kim, J. H.; Park, S. H.; Sun, Y. K. J. Electrochem. Soc. 2005, 152 (7), A1320-A1328.

(36) Aydinol, M. K.; Kohan, A. F.; Ceder, G.; Cho, K.; Joannopoulos, J. Phys. Rev. B 1997, 56 (3), 1354-1365.

(37) Bader, R. F. W. Atoms in Molecules - A Quantum Theory; Oxford University Press: New York, 1990.

(38) Kwon, K. D.; Refson, K.; Sposito, G. Phys. Rev. Lett. 2008, 100, 146601. 
Supplementary Information

\title{
Anomalous Pseudocapacitive Behavior of a Nanostructured, Mixed-Valent Manganese Oxide Film for Electrical Energy Storage
}

\author{
Min-Kyu Song ${ }^{1, \dagger}$, Shuang Cheng ${ }^{1, \dagger}$, Haiyan Chen $^{2}$, Wentao Qin ${ }^{1}$, Kyung-Wan \\ $\mathrm{Nam}^{3}$, Shucheng $\mathrm{Xu}^{4}$, Xiao-Qing Yang ${ }^{3}$, Angelo Bongiorno ${ }^{4}$, Jangsoo Lee ${ }^{5}$, Jianming \\ $\mathrm{Bai}^{6}$, Trevor A. Tyson ${ }^{2}$, Jaephil Cho ${ }^{5}$, and Meilin Liu ${ }^{1, *}$ \\ ${ }^{1}$ School of Materials Science and Engineering, Center for Innovative Fuel Cell and \\ Battery Technologies, Georgia Institute of Technology, 771 Ferst Drive, Atlanta, GA \\ 30332-0245, USA \\ ${ }^{2}$ Department of Physics, New Jersey Institute of Technology, Newark, NJ 07102, USA \\ ${ }^{3}$ Chemistry Department, Brookhaven National Laboratory, Upton, NY 11973, USA \\ ${ }^{4}$ School of Chemistry and Biochemistry, Georgia Institute of Technology, 901 Atlantic \\ Drive, Atlanta, GA 30332-0400, USA \\ ${ }^{5}$ Interdisciplinary School of Green Energy, Ulsan National Institute of Science \& \\ Technology (UNIST), 701-11,100 Banyeon-ri, Eonyang-eup, Ulju-gun, Ulsan, Korea, \\ 689-798 \\ ${ }^{6}$ High Temperature Materials Laboratory, Oak Ridge National Laboratory, Oak Ridge, \\ TN 37831, USA
}

$\dagger$ These authors contributed equally to this work.

*e-mail: meilin.liu@mse.gatech.edu 


\section{Methods}

Synthesis of novel electrodes. All chemicals were of analytical grade and used without further purification. In a typical synthesis procedure, several pieces of carbon fiber paper (Fuel cell store, 2050L) were added into $100 \mathrm{ml}$ of $2 \mathrm{M}$ sulfuric acid $\left(\mathrm{H}_{2} \mathrm{SO}_{4}\right.$ solution), pre-heated to a given temperature $\left(75^{\circ} \mathrm{C}\right)$ in a water bath with vigorous magnetic stirring with cool water fluxing in about $30 \mathrm{~min}$. One gram of $\mathrm{KMnO}_{4}$ was subsequently added to the solution which was kept for a predetermined period of time (2 30 minutes) with vigorous stirring. The morphology and nanostructure of $\mathrm{MnO}_{\mathrm{x}}$ coating can be tuned by adjusting the solution temperature $\left(60 \sim 90^{\circ} \mathrm{C}\right)$. The as-synthesized electrodes were then taken out, ultrasonically cleaned for several times with DI water and ethanol, dried at $80^{\circ} \mathrm{C}$ for about an hour, and annealed for 2 hours at different temperatures $(200,350,400$, $450^{\circ} \mathrm{C}$ ) in different atmospheres (air, $\mathrm{N}_{2}, 4 \% \mathrm{H}_{2}$ ) with a ramp rate of $3^{\circ} \mathrm{C} / \mathrm{min}$. It is noted that different types of carbon (e.g., carbon nanotubes and graphene) or different diameter of carbon fibers would require slightly different annealing conditions to form the mixedvalent $\mathrm{MnO}_{\mathrm{x}}$ film.

Electron microscopy. Scanning electron microscope (SEM Leo/Zeiss 1530) was operated at an accelerating voltage of $3 \mathrm{kV}$ and the high resolution transmission electron microscope (JEOL $4000 \mathrm{EX}$ ) was operated at an accelerating voltage of $400 \mathrm{kV}$.

Synchrotron-based X-ray analysis (Diffraction and Absorption). Synchrotron X-ray diffraction analyses, including glancing angle and time-resolved X-ray diffraction, were carried out with the beamline X14A of the National Synchrotron Light Source (NSLS) at Brookhaven National Laboratory. Diffraction patterns were collected with a high resolution Si strip detector of 640 pixels, with each pixel corresponding to $0.005^{\circ}$. For insitu XRD studies, each as-synthesized sample was loaded into a quartz capillary (inner diameter $0.7 \mathrm{~mm}$ ) of a flow cell and air was admitted into the cell at a rate of $10 \mathrm{~mL} / \mathrm{min}$. The resistive heating of the capillary was program-controlled by a temperature controller (Eurotherm 818 ) and monitored with a 0.5 - $\mathrm{mm}$ type $\mathrm{K}$ thermocouple inside the capillary. Phase identifications were performed using software Jade 6.5 (Materials Data INC). The ex situ X-ray absorption (XANES and XAFS) data were collected at NSLS beamline 
$\mathrm{X} 3 \mathrm{~B}$. The measurements were collected in fluorescence mode using a 13-element $\mathrm{Ge}$ detector. A Mn metal powder sample was used for energy calibration. In situ Mn K-edge XAS during charge-discharge of the cell was measured at the beamlines X18A and X19A in a fluorescence mode using a PIPS detector. The reference Mn foil spectra were also measured simultaneously in a transmission mode for an energy calibration.

Electrochemical characterization. Cyclic voltammetry (CV) curves and galvanostatic charge-discharge curves were recorded at room temperature in a symmetric-cell configuration containing $1 \mathrm{M} \mathrm{Na}_{2} \mathrm{SO}_{4}$ electrolyte solution. The Whatman filters (GF/D) were used as separators and typical area of single electrode was $\sim 1.98 \mathrm{~cm}^{2}$. It is noted that, due to the macro-porous feature of CFP and thin, conformal coating of $\mathrm{MnO}_{\mathrm{x}}$ film, scaleup can be easily made by stacking the electrodes up to several layers without compromising excellent performance (Fig. S17). The potential and current were controlled by an Electrochemical Interface (Solartron, SI 1286) and the electrochemical impedance spectroscopy (EIS) analysis was conducted using a Frequency Response Analyzer (Solartron SI 1255) and SI 1286 with an applied ac voltage of $10 \mathrm{mV}$ in the frequency range of $0.001 \mathrm{~Hz}$ to $1 \mathrm{MHz}$.

The symmetrical cell of "two identical electrodes" was used for estimation of specific capacitances, energy density and power density, except when we examined the electrochemical behavior of the active electrode materials using three-electrode configurations (e.g., with respect to a reference electrode, Figure S16). When a symmetric cell of "two identical electrodes" is used, the apparent capacitance of the cell, $\mathrm{C}_{\text {total, }}$, is related to the capacitances of two electrodes as follows,

$$
\frac{1}{C_{\text {total }}}=\frac{1}{C_{+}}+\frac{1}{C_{-}}
$$

where $\mathrm{C}_{+}$and $\mathrm{C}_{-}$are the capacitance of each single electrode in the symmetrical cell. When the two electrodes are "identical" (i.e., $C_{+} \approx C_{-}$), the capacitance of each single electrode can be calculated from the capacitance of the cell as follows,

$$
C_{+} \approx C_{-} \approx 2 C_{\text {Total }}
$$


The capacitance was calculated from the slope of the discharge curve from the following equation:

$$
C_{\text {Total }}=\frac{I}{\left(\frac{d V}{d t}\right)}
$$

where $C_{\text {Total }}$ is the capacitance of the symmetric cell in Farad (F), $I$ is the discharge current in Ampere (A) and $d V / d t$ is the slope of the discharge curve in Volts per second $(\mathrm{V} / \mathrm{s})$. Thus, the specific capacitance of active material $(\mathrm{F} / \mathrm{g})$ per single electrode is related to the capacitance of the symmetric cell, $C_{\text {Total }}$, as follows,

$$
C_{m, A M}=\frac{2 C_{\text {Total }}}{m_{A M}}
$$

where $m_{A M}$ is the weight $(\mathrm{g})$ of the active material $\left(\mathrm{MnO}_{\mathrm{x}}\right)$ per single electrode.

The maximum stored energy (E) and the peak power (P) of electrochemical capacitors are given by equations (4) and (5), respectively, where $\mathrm{C}$ is the capacitance in Farads, $\mathrm{V}$ is the operating voltage in volts, and $\mathrm{R}$ is the equivalent series resistance in ohms.

$$
\begin{aligned}
& E=\frac{1}{2} C V^{2} \\
& P=\frac{V^{2}}{4 R}
\end{aligned}
$$

The power density was calculated by dividing the energy density by the discharge time (h) at different current densities. The calculated energy and power densities were then normalized by the weight of active materials $\left(0.32 \mathrm{mg}, \mathrm{MnO}_{\mathrm{x}}\right)$ of single electrode. Further information about these calculations can be found elsewhere ${ }^{1,2}$.

Other characterization. The thermogravimetric analysis (TGA) was used to determine the weight of the $\mathrm{MnO}_{\mathrm{x}}$ loaded to $\mathrm{CFP}$ with a heating rate of $25^{\circ} \mathrm{C} / \mathrm{min}$. Typical weight of $\mathrm{MnO}_{\mathrm{x}}$ in single electrode ranged from $\sim 0.32 \mathrm{mg}$ to $\sim 2.8 \mathrm{mg}$ depending on the deposition time (2 30 minutes). The thicknesses of the $\mathrm{MnO}_{\mathrm{x}}$ coatings were determined from microscopy. Gas adsorption analysis (BELSORP-max, BEL JAPAN, INC) was 
performed to evaluate the specific surface area (Brunauer-Emmett-Teller, BET), specific pore volumes, average pore size and nitrogen adsorption/desorption isotherm.

Computational methods. DFT calculations were performed using the Vienna Ab-initio Simulation Package (VASP) ${ }^{3,4}$. An energy cutoff of $400 \mathrm{eV}$ was used for the plane wave basis set, ionic cores were treated by using the projector augmented wave method ${ }^{3,4}$, and the exchange and correlation energy was accounted for within the generalized gradient approximation proposed by Perdew, Burke, and Ernzerhof $(\mathrm{PBE})^{5}$. To describe appropriately the manganese oxides, we employed a $\mathrm{PBE}+\mathrm{U}$ scheme following the approach of Dudarev ${ }^{6}$ with a value for $\mathrm{U}-\mathrm{J}$ equal to $4 \mathrm{eV}^{7}$. Surface calculations were carried out using a slab of crystalline $\mathrm{Mn}_{3} \mathrm{O}_{4}$ (Hausmannite, space group I41/amd), exposing (001) surfaces to a vacuum region of $12 \AA$. Calculations were carried out by using a $3 \times 3 \times 1$ Monkhorst-Pack grid. To model the experimental conditions, O-atoms on the surface were terminated by $\mathrm{H}$ atoms. The excess charge added to the slab was $0.5 \mathrm{e}$ per formula unit. The charge density obtained from the VASP calculations was analyzed according to the Quantum Theory of Atoms in Molecules ${ }^{8}$. 


\section{Supplementary Figures and Discussion}
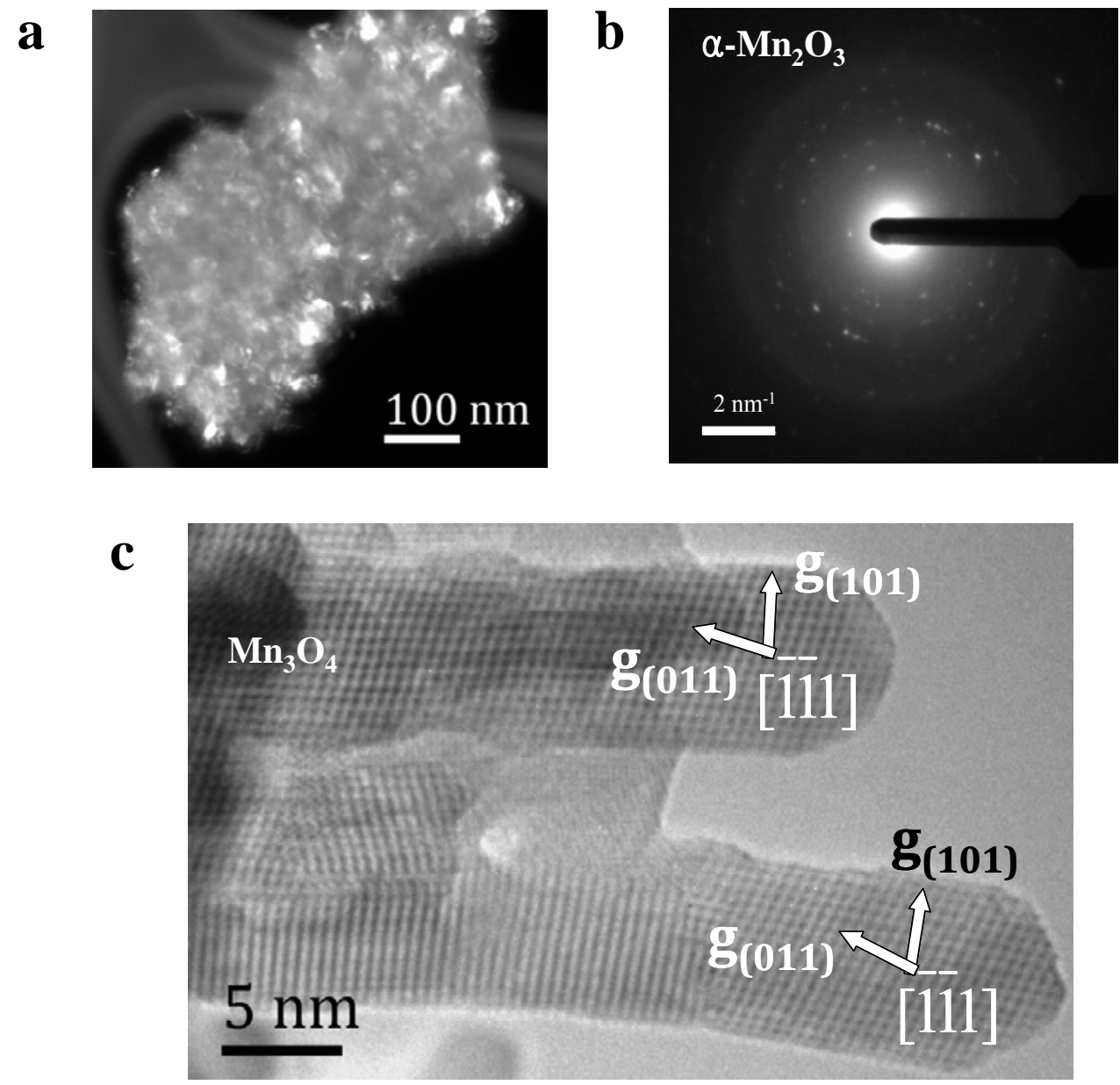

Fig. S1. a, A dark-field image of a portion of a crushed $\mathrm{MnO}_{\mathrm{x}}$ coated $\mathrm{CFP}$ after annealing in air at $400^{\circ} \mathrm{C}$ for $2 \mathrm{~h}$. b, Selected area electron diffraction (SAED) pattern of the sample shown in (a). c, High resolution TEM image showing the [1111]zone-axis fringes of two $\mathrm{Mn}_{3} \mathrm{O}_{4}$ nano-needles, whose diameters are on the order of a few nanometers.

The $\mathrm{MnO}_{\mathrm{x}}$ coated CFP sample was rigorously pestled in a mortar to a fine powder form. The fine powders were dispersed in isopropyl alcohol, and subsequently loaded on a lacey carbon film on a $\mathrm{Cu}$ grid. Figure (a) reveals the low aspect-ratio particles in the size 
range of tens of nanometers; in addition, there are many smaller crystals of a few nanometers lit up. The SAED pattern shown in Fig. (b) shows many discrete and conspicuous diffraction spots, all of which can be indexed with the crystalline $\alpha-\mathrm{Mn}_{2} \mathrm{O}_{3}$ with a lattice constant of $0.94 \mathrm{~nm}$. The lattice fringes shown in Fig. (c) reveal $\mathrm{Mn}_{3} \mathrm{O}_{4}$ crystals grown with strongly preferred orientation parallel to the (101) lattice planes. Since both the (101) and the (011) spacing are the largest lattice spacing in $\mathrm{Mn}_{3} \mathrm{O}_{4}$ lattice, such an orientation provides the maximum opening of the lattice to the outside of the nano-needle and may facilitate the incorporation and transport of ions along this direction. 
a

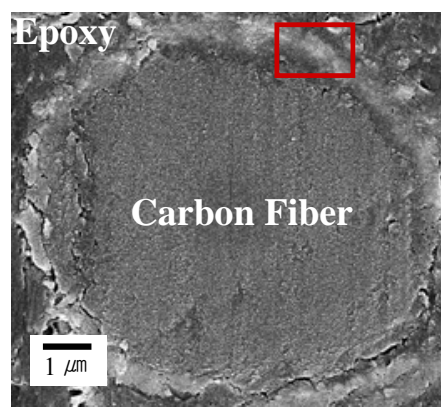

b

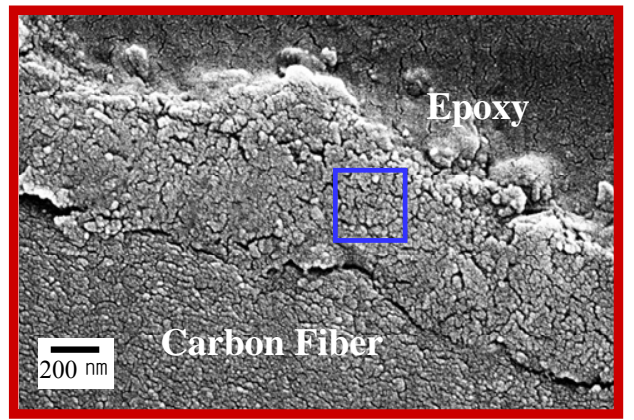

c

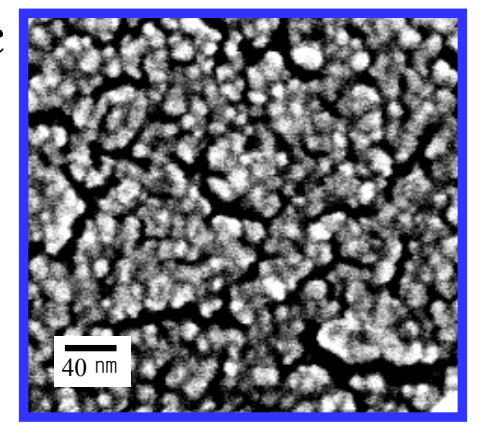

d

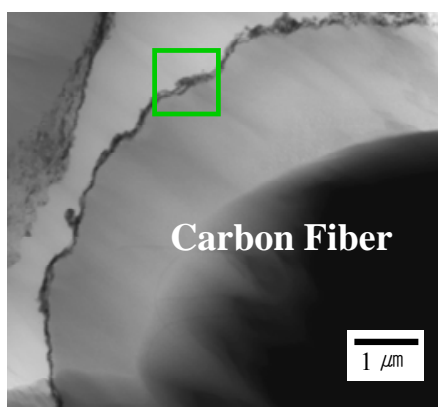

$\mathbf{e}$

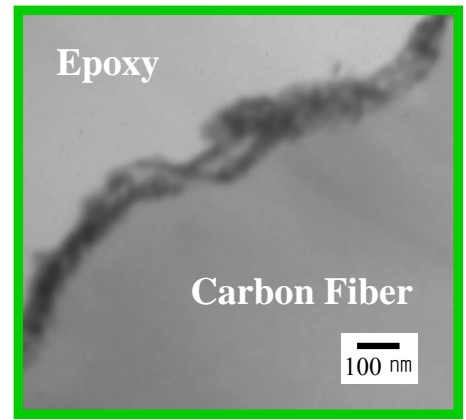

Fig. S2. a, Cross-sectional SEM image of $\mathrm{MnO}_{\mathrm{x}} / \mathrm{CFP}$ deposited for 30 minutes. b, An enlarged view of the area highlighted with a red rectangle in (a) showing the details of the $\mathrm{MnO}_{\mathrm{x}}$ coating. c, An enlarged view of the area highlighted with a blue square in (b) showing the porous morphology of the $\mathrm{MnO}_{\mathrm{x}}$ layer. d, A cross-sectional TEM image of $\mathrm{MnO}_{\mathrm{x}} / \mathrm{CFP}$ deposited for 2 minutes. e, An enlarged view of the area highlighted with a green square in $(\mathrm{d})$ showing the thin $\mathrm{MnO}_{\mathrm{x}}$ coating.

We have carefully examined the cross-sectional views of $\mathrm{MnO}_{\mathrm{x}}$-coated CFP with different loading of $\mathrm{MnO}_{\mathrm{x}}$ (by deposition for a period of 2, 5, 15, and 30 minutes). Shown in Fig. S2 are some typical TEM (deposition of $\mathrm{MnO}_{\mathrm{x}}$ for $2 \mathrm{~min}$ ) and SEM (deposition of $\mathrm{MnO}_{\mathrm{x}}$ for $30 \mathrm{~min}$ ) images of $\mathrm{MnO}_{\mathrm{x}}$-coated CFP electrodes. The thicknesses of the $\mathrm{MnO}_{\mathrm{x}}$ coatings can be readily seen from these images. Fig. S2 (a) shows a low-magnification cross-sectional view of a $\mathrm{MnO}_{\mathrm{x}}$ coating deposited for 30 minutes on a carbon fiber of 8- 
$10 \mu \mathrm{m}$ in diameter. The average thickness of the $\mathrm{MnO}_{\mathrm{x}}$ coating is $\sim 800 \mathrm{~nm}$. Fig. S2 (c) reveals the porous structure of the $\mathrm{MnO}_{\mathrm{x}}$ coating. For the sample prepared by deposition of $\mathrm{MnO}_{\mathrm{x}}$ for $2 \mathrm{~min}$, a very thin coating of porous $\mathrm{MnO}_{\mathrm{x}}$ was observed along the perimeter of the carbon fibers, as seen in Figure S2 (e). The average thickness is $\sim 70 \mathrm{~nm}$. 

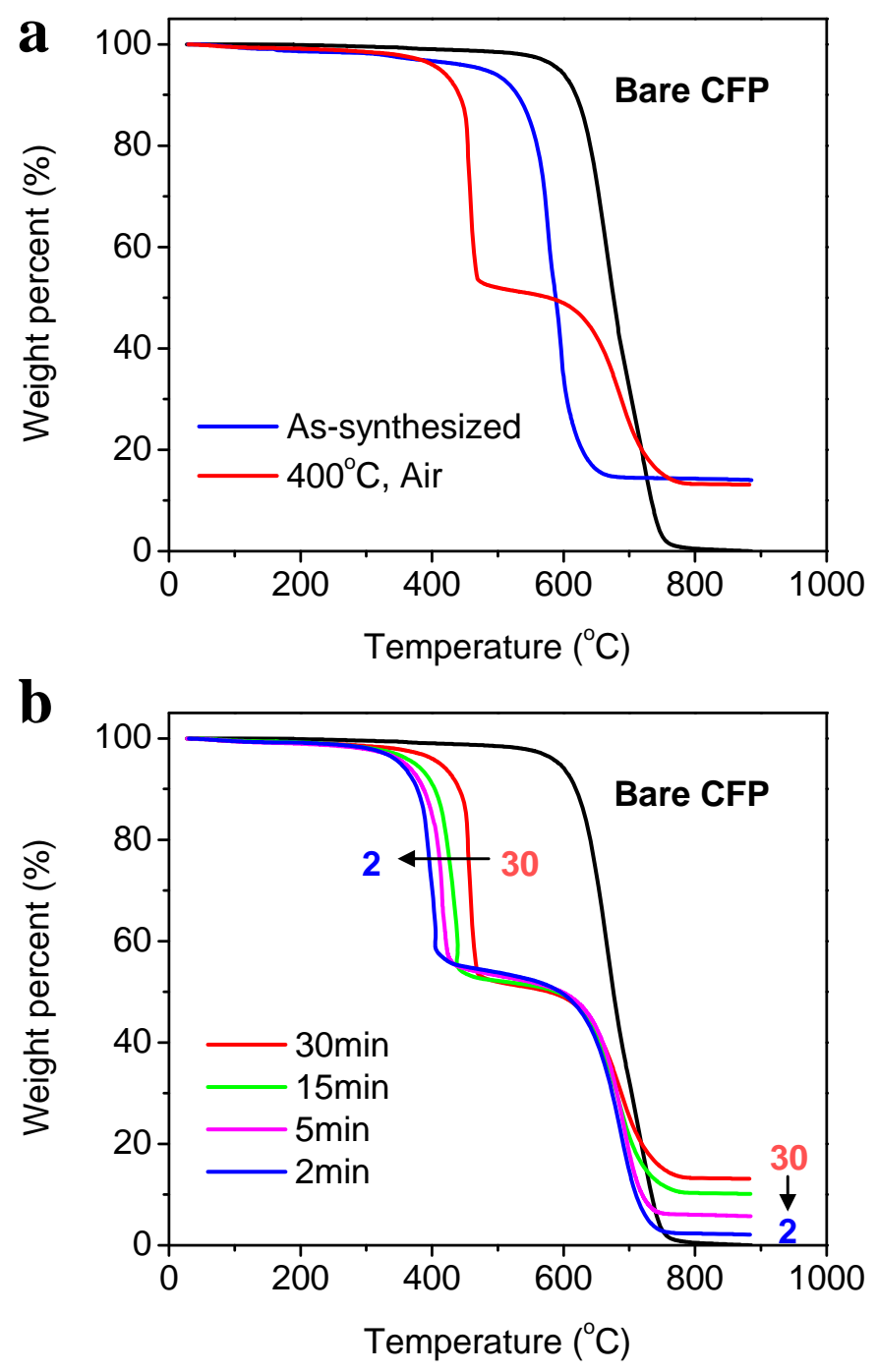

Fig. S3. a, TGA curves of bare CFP, as-synthesized $\mathrm{MnO}_{2}$ on $\mathrm{CFP}$, and mixed-valent $\mathrm{MnO}_{\mathrm{x}}$ after heat-treatment at $400^{\circ} \mathrm{C}$ for $2 \mathrm{~h}$. Both samples were deposited for 30 minutes. b, TGA curves of mixed-valent $\mathrm{MnO}_{\mathrm{x}}$ deposited for different time (2 30 minutes).

We used thermogravimetric analysis (TGA) to determine the total weight of each $\mathrm{MnO}_{\mathrm{x}}$ coated CFP sample (the initial weight of the sample at room temperature after heattreatment at $400^{\circ} \mathrm{C}$ for $2 \mathrm{~h}$ ) and the weight of the $\mathrm{MnO}_{\mathrm{x}}$ loaded to $\mathrm{CFP}$ (the final weight 
of the sample above $800^{\circ} \mathrm{C}$ when all carbon were removed). We repeated the measurements many times and the standard deviation was $\sim 2.8 \%$.

As shown in Fig. S3a, while bare CFP was totally burned out above $800^{\circ} \mathrm{C}$, TGA curve of as-synthesized electrode (prepared by deposition of amorphous $\mathrm{MnO}_{2}$ for 30 minutes) indicated the weight of remaining $\mathrm{MnO}_{2}$ is 14.3 wt.\% of total electrode. The combustion (i.e. oxidation) of carbon started earlier (at $\sim 530^{\circ} \mathrm{C}$ ) for the as-synthesized sample than for the bare CFP (at $\sim 630^{\circ} \mathrm{C}$ ) due to catalytic combustion caused by manganese oxide. Interestingly, the TGA curve appears quite different for the samples annealed at $400^{\circ} \mathrm{C}$ in air for $2 \mathrm{~h}$, which led to formation of mixed-valent $\mathrm{MnO}_{\mathrm{x}}$ on the CFP. The catalytic combustion of carbon started even earlier (at $\sim 430^{\circ} \mathrm{C}$ ) than the amorphous $\mathrm{MnO}_{2}$ and showed a two-step oxidation process. The first dramatic weight loss is attributed to the oxidation of thin carbon layer in the proximity to the $\mathrm{MnO}_{\mathrm{x}}$ coating.

The TGA curves of $\mathrm{MnO}_{\mathrm{x}} / \mathrm{CFP}$ electrode deposited for 2, 5, 15 and 30 minutes are shown in Fig. S3b. Our best performance $(\sim 2,530 \mathrm{~F} / \mathrm{g})$ was achieved with the $\mathrm{MnO}_{\mathrm{x}} / \mathrm{CFP}$ electrode prepared by deposition of $\mathrm{MnO}_{\mathrm{x}}$ for $2 \mathrm{~min}$. The weight $\%$ of $\mathrm{MnO}_{\mathrm{x}}$ deposited for $2,5,15$, and 30 minutes were determined to be $\sim 2.3 \%, \sim 4.8 \%, \sim 10.3 \%$ and $\sim 13.3 \%$, respectively. The thicknesses of the $\mathrm{MnO}_{\mathrm{x}}$ coatings (determined from microscopy), together with the corresponding weights of $\mathrm{MnO}_{\mathrm{x}}$ (determined from TGA), are plotted as a function of the deposition time in Fig. S4. 


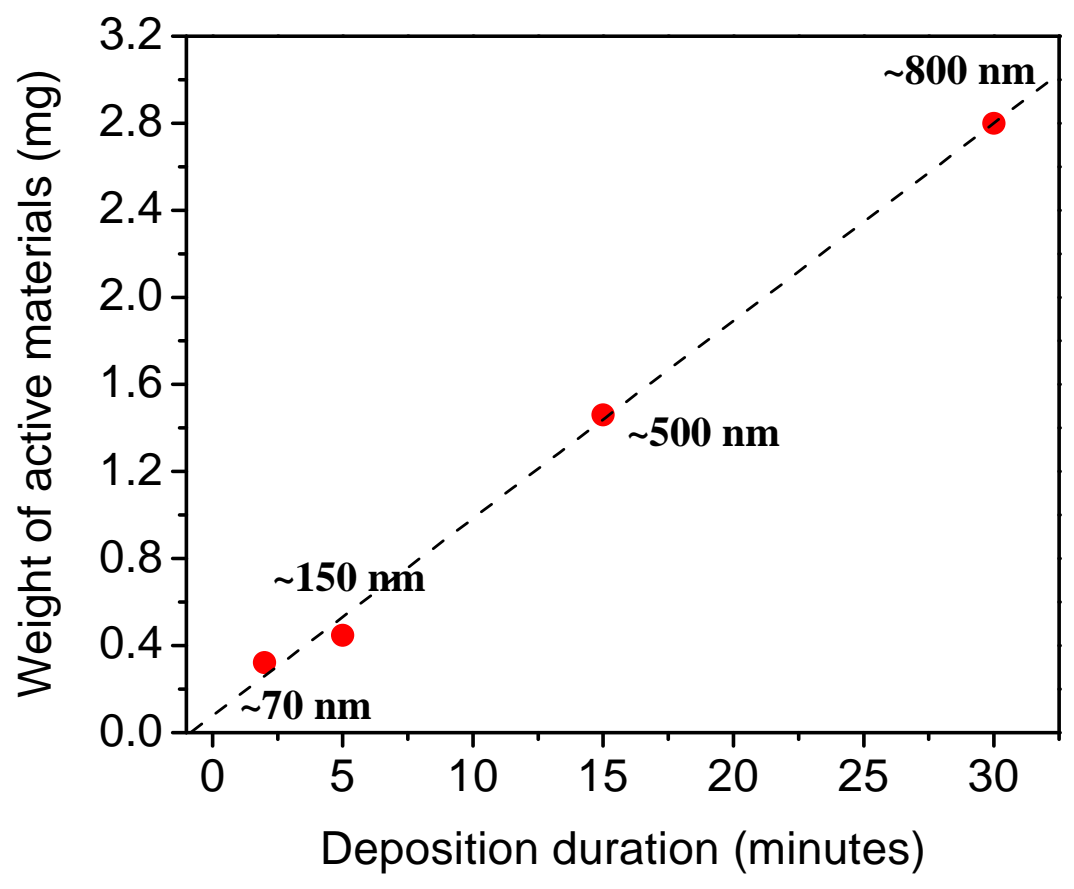

Fig. S4. The thickness and the weight of the $\mathrm{MnO}_{\mathrm{x}}$ coating of single electrode with a superficial area of $\sim 1.98 \mathrm{~cm}^{2}$. The weights of $\mathrm{MnO}_{\mathrm{x}}$ were determined using TGA whereas the thickness was determined by electron microscopy. 


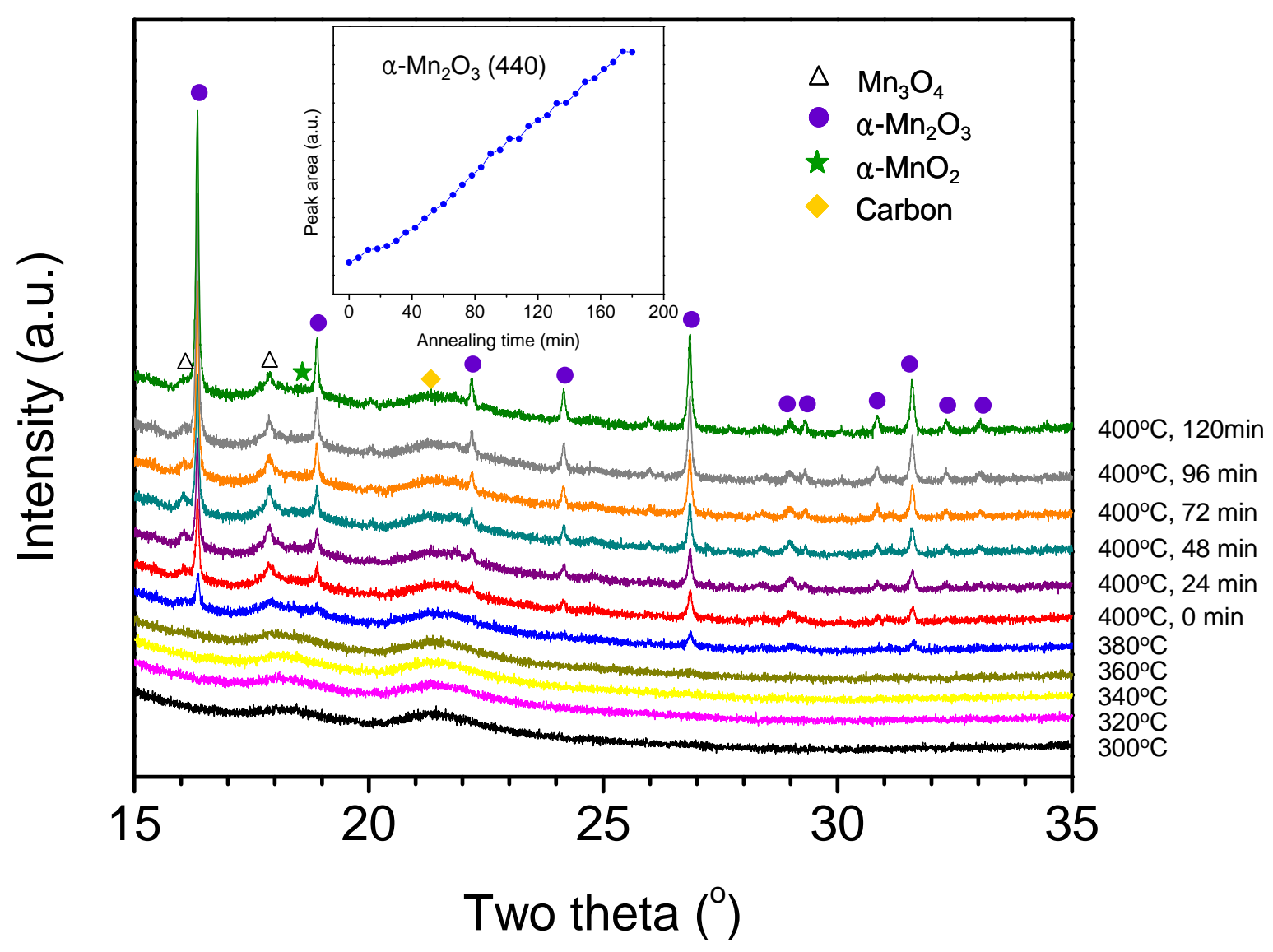

Fig. S5. In-situ synchrotron-based XRD patterns (transmission mode) of $\mathrm{MnO}_{\mathrm{x}}$ coating measured at different temperatures and annealing times. The patterns reveal that small crystalline phases started to form above $360^{\circ} \mathrm{C}$. At $400^{\circ} \mathrm{C}$, sharp peaks of crystalline $\alpha$ $\mathrm{Mn}_{2} \mathrm{O}_{3}$ appeared with small amounts of $\mathrm{Mn}_{3} \mathrm{O}_{4}$ and $\alpha-\mathrm{MnO}_{2}$. The $\alpha-\mathrm{Mn}_{2} \mathrm{O}_{3}$ peak intensities grow with annealing time as shown in the insert, indicating that the volume fraction of the phase increased with annealing time. In contrast, the intensities of the $\mathrm{Mn}_{3} \mathrm{O}_{4}$ peaks decreased slightly with annealing time at $400^{\circ} \mathrm{C}$. The $\mathrm{Mn}_{3} \mathrm{O}_{4}$ phase disappeared after annealing at $400^{\circ} \mathrm{C}$ in air for 3 hours (the result is not shown). 


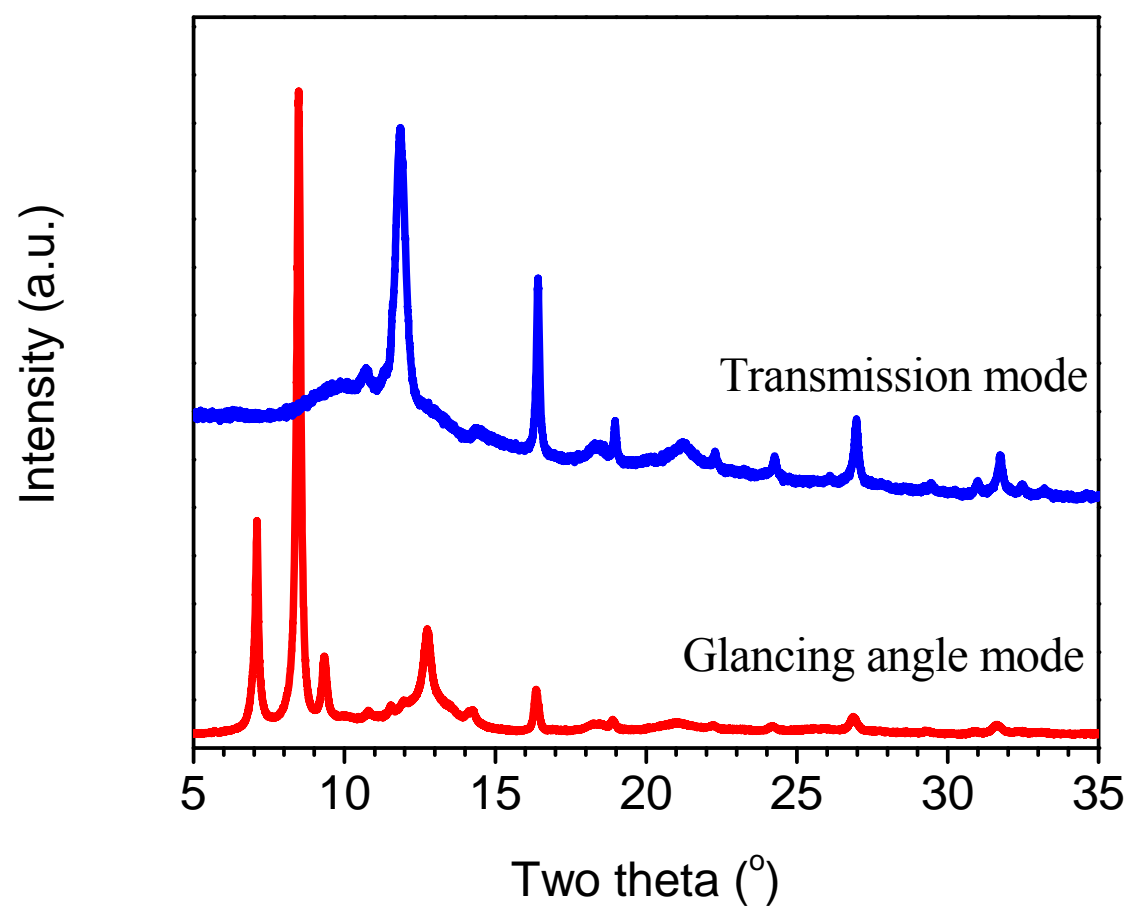

Fig. S6. Synchrotron-XRD patterns of $\mathrm{MnO}_{\mathrm{x}}$ deposited for 30 minutes and annealed at $400^{\circ} \mathrm{C}$ in air for $2 \mathrm{~h}$. The differences between the patterns acquired in a transmission mode and a glancing angle $\left(0.1^{\circ}\right)$ mode suggest that the phases on the surface are very different from those in the bulk. 

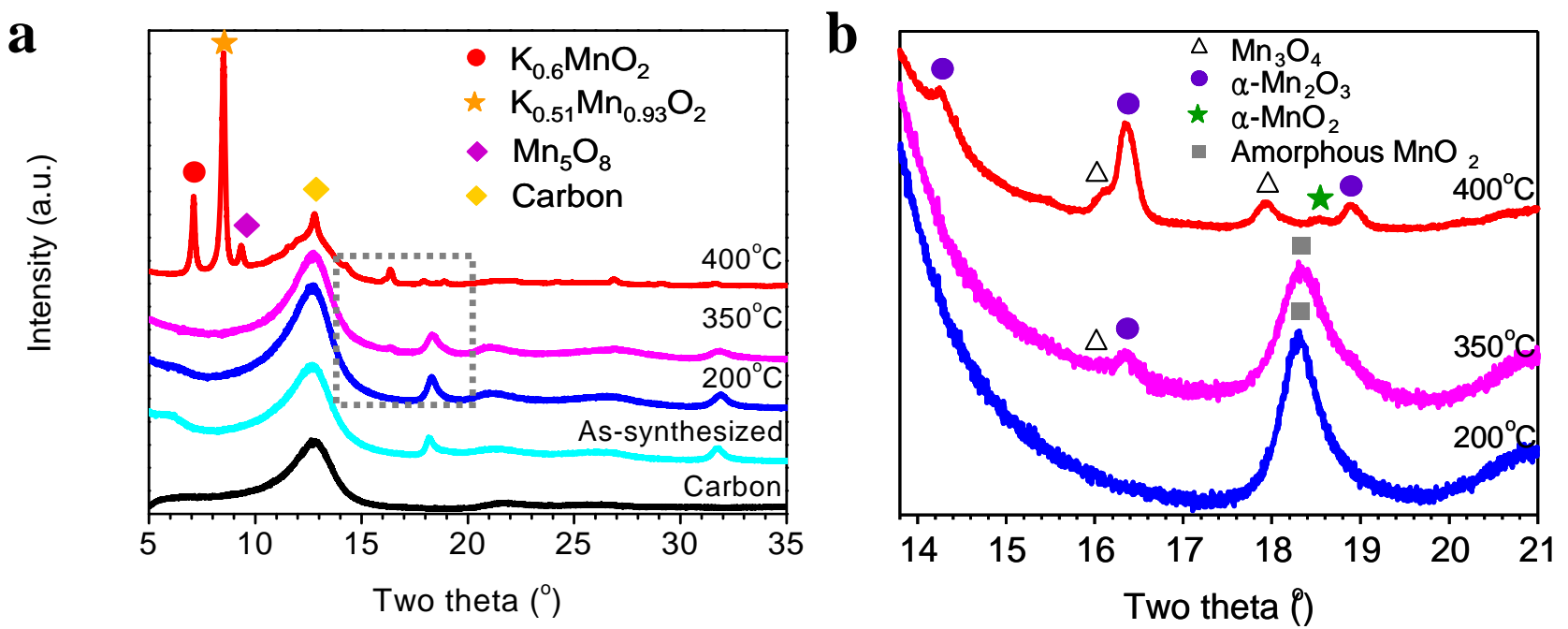

Fig. S7. a, Synchrotron-XRD patterns acquired at an incident glancing angle of $0.2^{\circ}$ for different samples of carbon, as-coated electrode, and coated electrode annealed at different temperatures in air for $2 \mathrm{~h}$. It appears that the surface phases (K-incorporated $\mathrm{MnO}_{2}, \mathrm{Mn}_{5} \mathrm{O}_{8}$, and $\mathrm{Mn}_{3} \mathrm{O}_{4}$, ) were formed at $\sim 400^{\circ} \mathrm{C}$. b, Enlarged view of the XRD pattern in the range of $14 \sim 21^{\circ}$ as highlighted in (a), confirming that crystalline $\alpha-\mathrm{Mn}_{2} \mathrm{O}_{3}$ appeared at $\sim 400^{\circ} \mathrm{C}$ with small amounts of $\mathrm{Mn}_{3} \mathrm{O}_{4}$ and $\alpha-\mathrm{MnO}_{2}$. Also, it is noted that small $\alpha-\mathrm{Mn}_{2} \mathrm{O}_{3}$ peaks started to appear at $350^{\circ} \mathrm{C}$. 

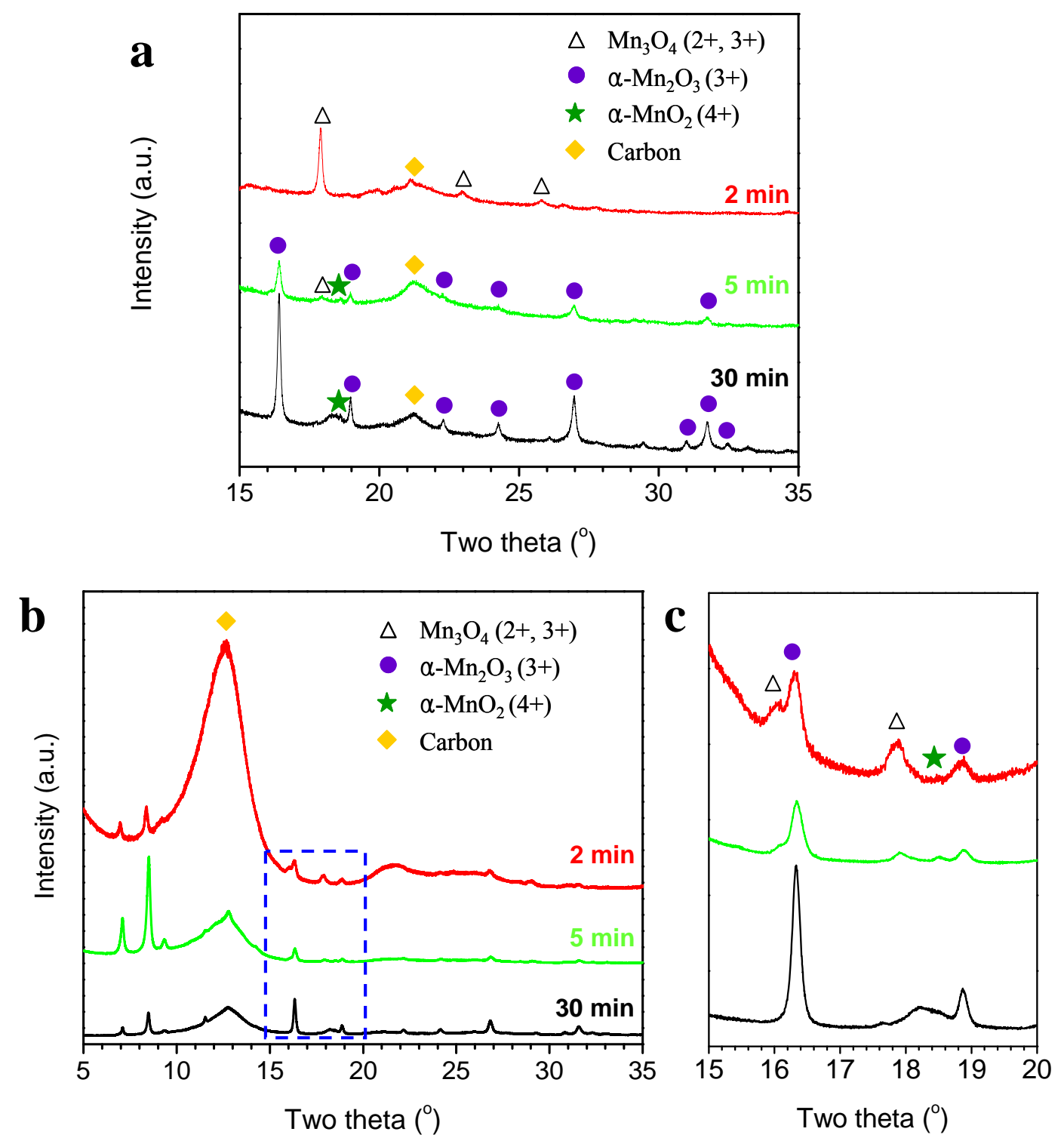

Fig. S8. Synchrotron X-ray diffraction (XRD) analysis. a, Transmission mode XRD pattern of $\mathrm{MnO}_{\mathrm{x}}$ electrodes deposited for 2, 5, and 30 minutes followed by annealing at $400^{\circ} \mathrm{C}$ in air for $2 \mathrm{~h}$. b, Glancing angle mode $\left(0.2^{\circ}\right)$ XRD pattern of $\mathrm{MnO}_{\mathrm{x}}$ electrodes deposited for 2, 5, and 30 minutes followed by annealing at $400^{\circ} \mathrm{C}$ in air for $2 \mathrm{~h}$. c, Enlarged view of XRD pattern between $15 \sim 20^{\circ}$ of XRD pattern of $\mathrm{MnO}_{\mathrm{x}}$ highlighted in (b). 


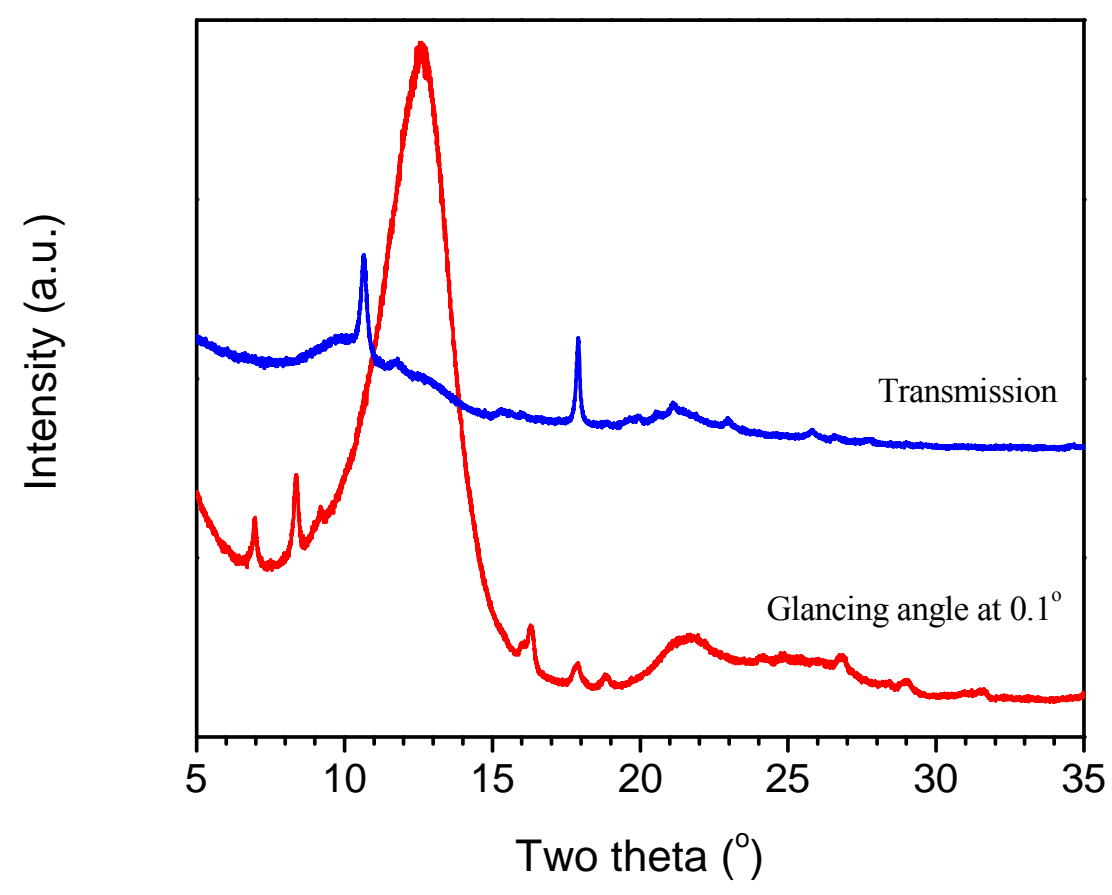

Fig. S9. Synchrotron-XRD patterns of $\mathrm{MnO}_{\mathrm{x}}$ deposited for 2 minutes and annealed at $400^{\circ} \mathrm{C}$ in air for $2 \mathrm{~h}$. The differences between the patterns acquired in a transmission mode and a glancing angle $\left(0.1^{\circ}\right)$ mode suggest that the phases on the surface are very different from those in the bulk. 


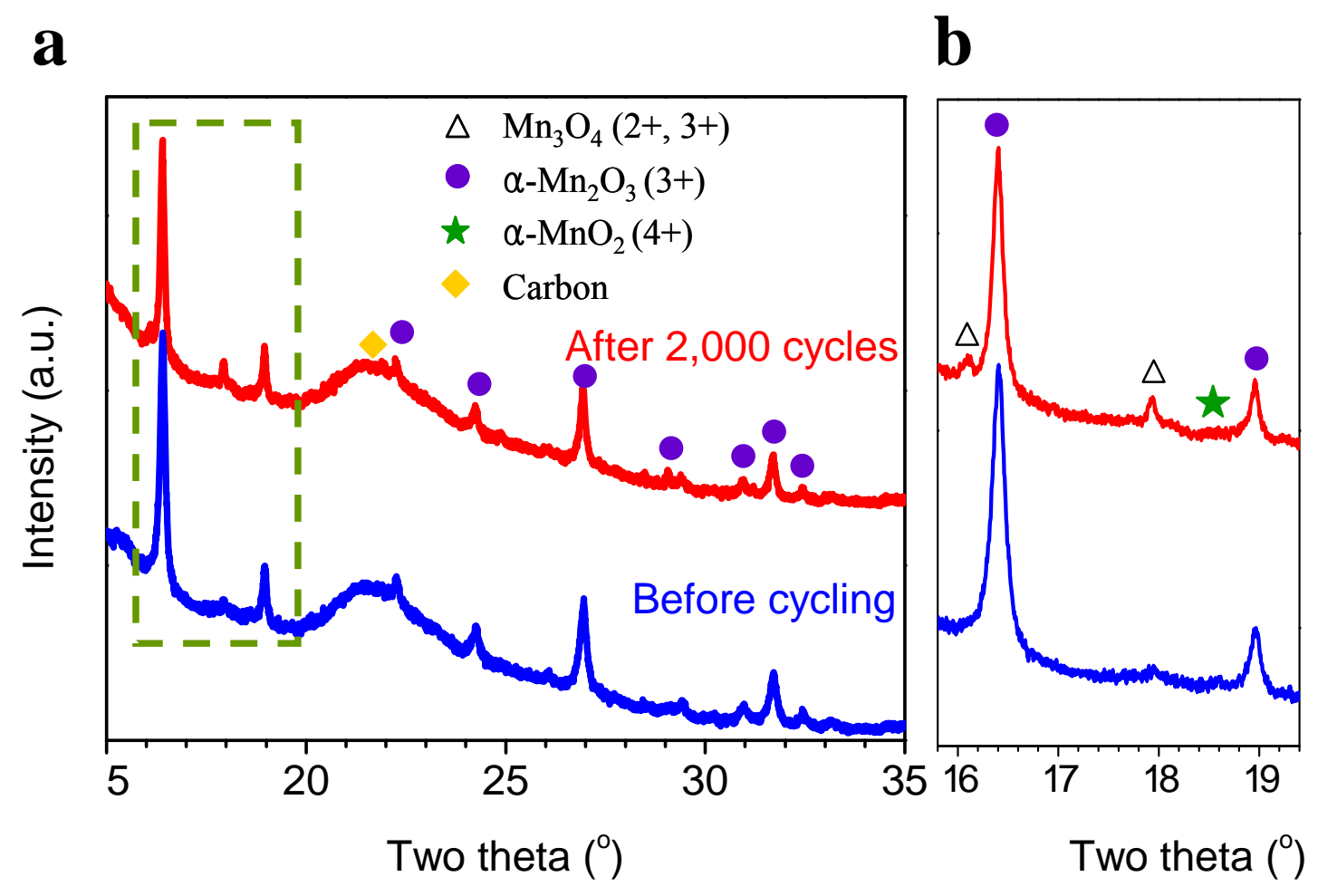

Fig. S10. a, Synchrotron X-ray diffraction (XRD) pattern (Transmission mode) of $\mathrm{MnO}_{\mathrm{x}}$ electrodes before and after 2,000 cycles, b, Enlarged view of XRD pattern of $\mathrm{MnO}_{\mathrm{x}}$ highlighted in (a). The mixed-phases $\left(\mathrm{Mn}_{3} \mathrm{O}_{4}, \alpha-\mathrm{Mn}_{2} \mathrm{O}_{3}\right.$ and $\left.\alpha-\mathrm{MnO}_{2}\right)$ were retained after 2,000 cycles and the peak intensity of $\mathrm{Mn}_{3} \mathrm{O}_{4}$ slightly increased. 

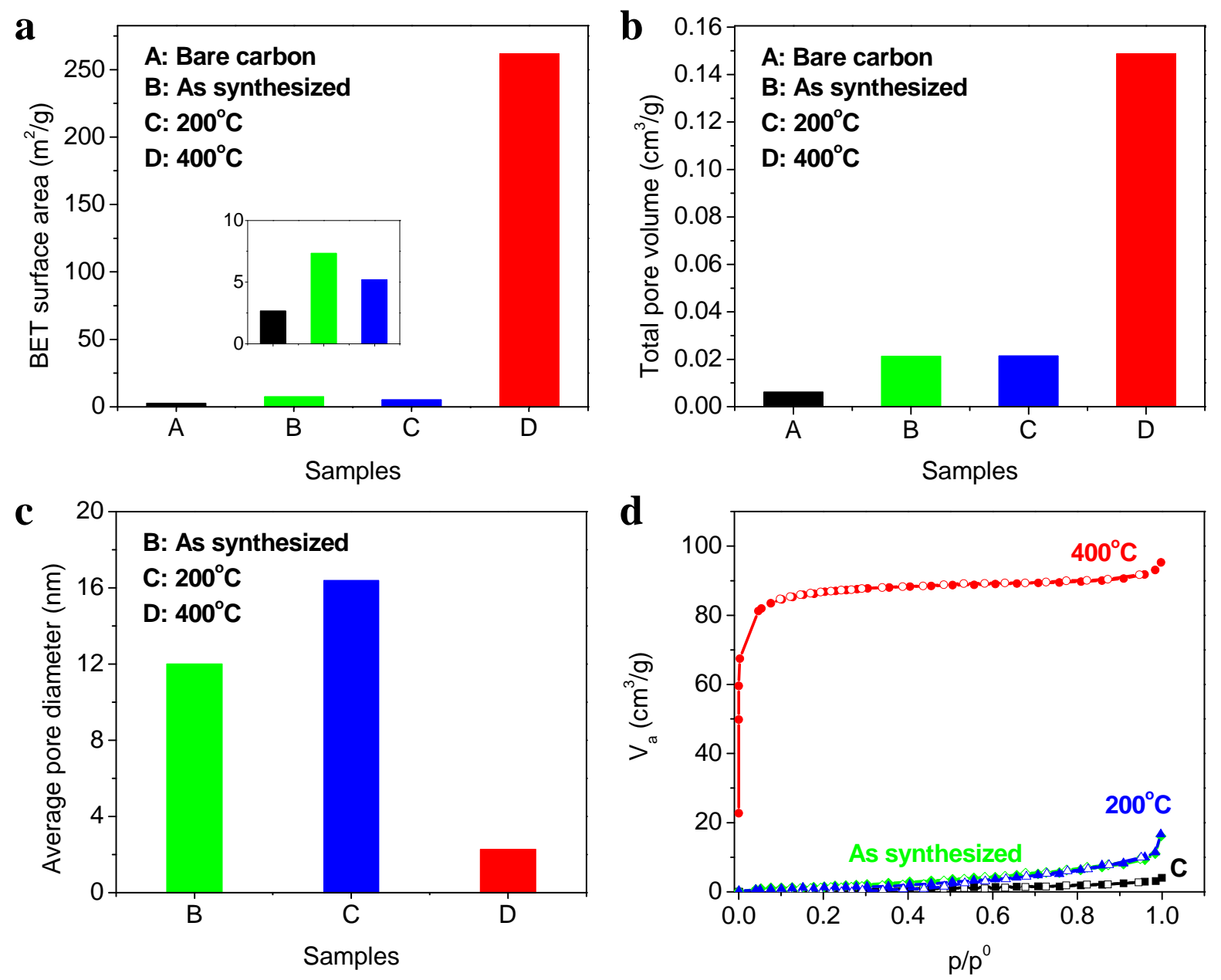

Fig. S11. Gas adsorption/desorption analysis of carbon, as-synthesized $\mathrm{MnO}_{\mathrm{x}}$ sample, and $\mathrm{MnO}_{\mathrm{x}}$ samples annealed at 200 and $400^{\circ} \mathrm{C}$ in air for $2 \mathrm{~h}$. a, BET surface areas. $\mathbf{b}$, Total pore volumes. c, Average pore diameters. d, Nitrogen adsoption/desorption isotherm. These results suggest that the microstructure of the $\mathrm{MnO}_{\mathrm{x}}$ underwent a dramatic rearrangement during annealing at $400^{\circ} \mathrm{C}$ in air for $2 \mathrm{~h}$, producing porous, nano-structured multi-valent $\mathrm{MnO}_{\mathrm{x}}$. 

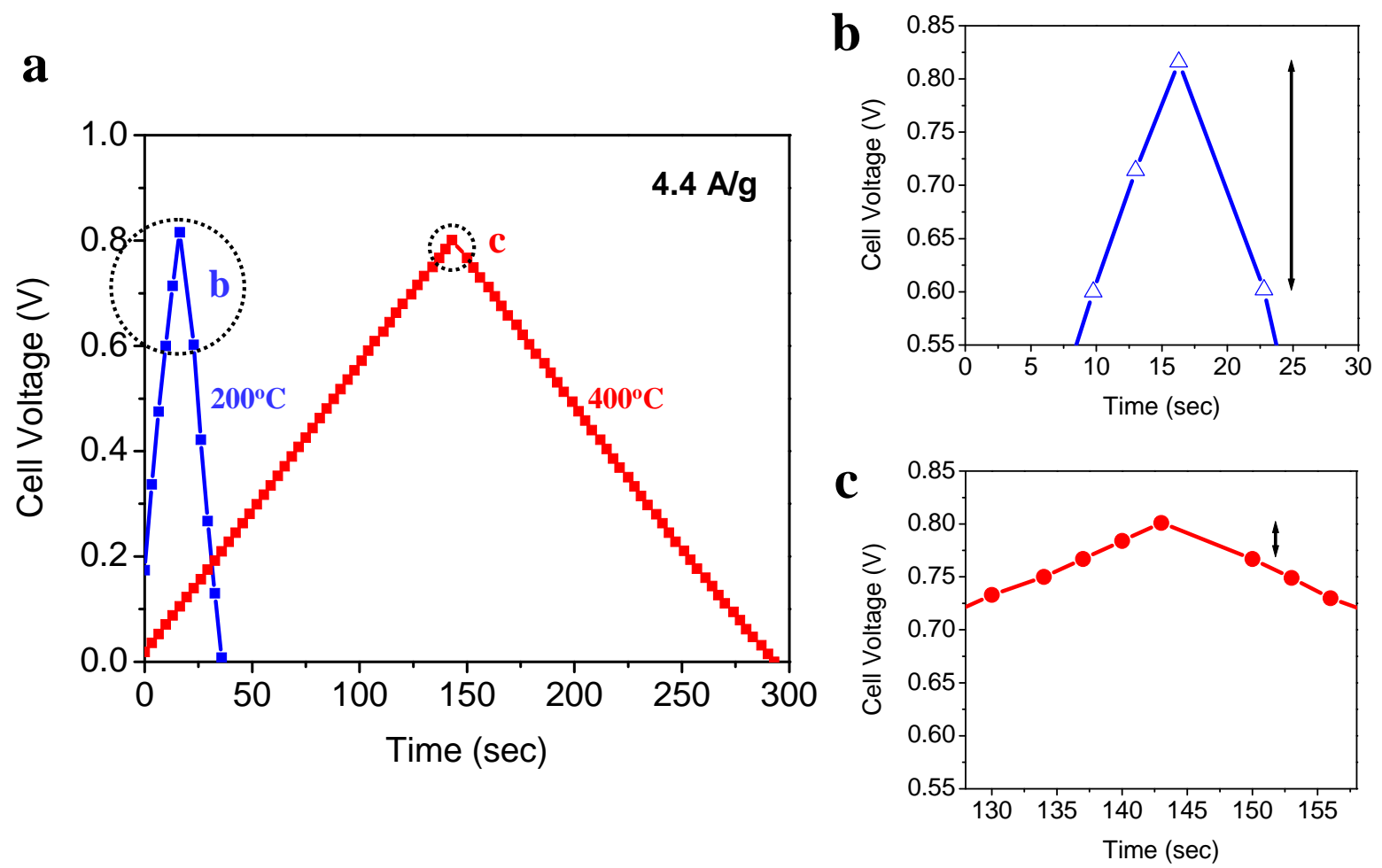

Fig. S12. a, Typical charge-discharge curves of symmetric pseudocapacitors constructed from amorphous $\mathrm{MnO}_{2}$ and mixed-valent $\mathrm{MnO}_{\mathrm{x}}$ electrodes at a constant current of 4.4 A/g. b, Enlarged views of iR drop of amorphous $\mathrm{MnO}_{2}$ highlighted in (a). c, Enlarged views of $\mathrm{iR}$ drop of mixed-valent $\mathrm{MnO}_{\mathrm{x}}$ electrodes highlighted in (a). 


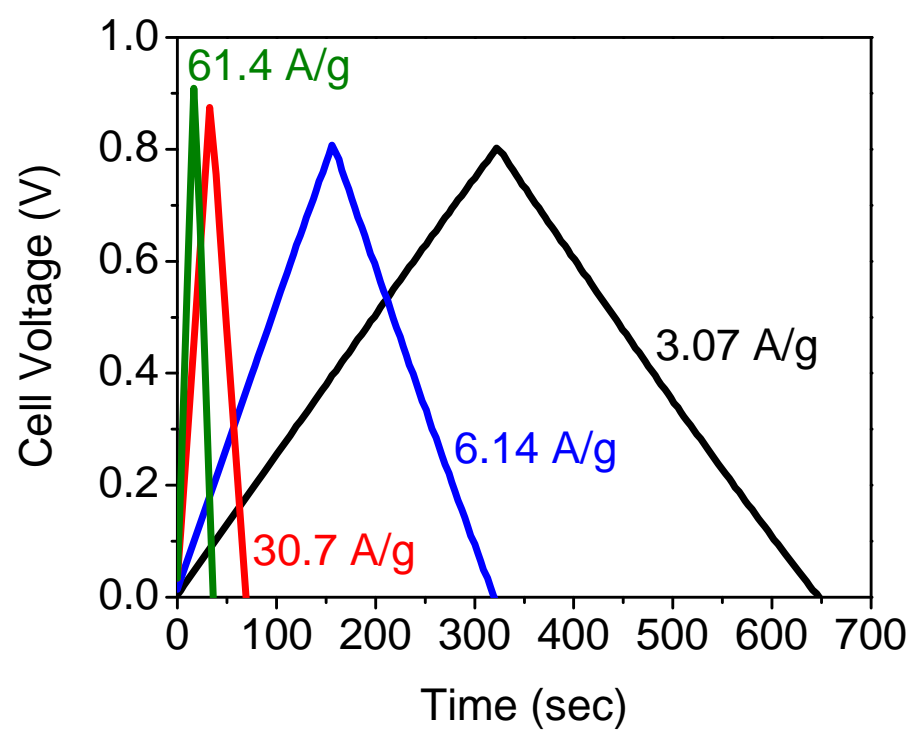

Fig. S13. Typical charge-discharge curves of symmetric pseudocapacitors constructed from mixed-valent $\mathrm{MnO}_{\mathrm{x}}$ electrodes with $\mathrm{Na}^{+}$at different constant currents. The "linear" and symmetrical charge-discharge curves imply that surface reactions are highly reversible and very fast. 

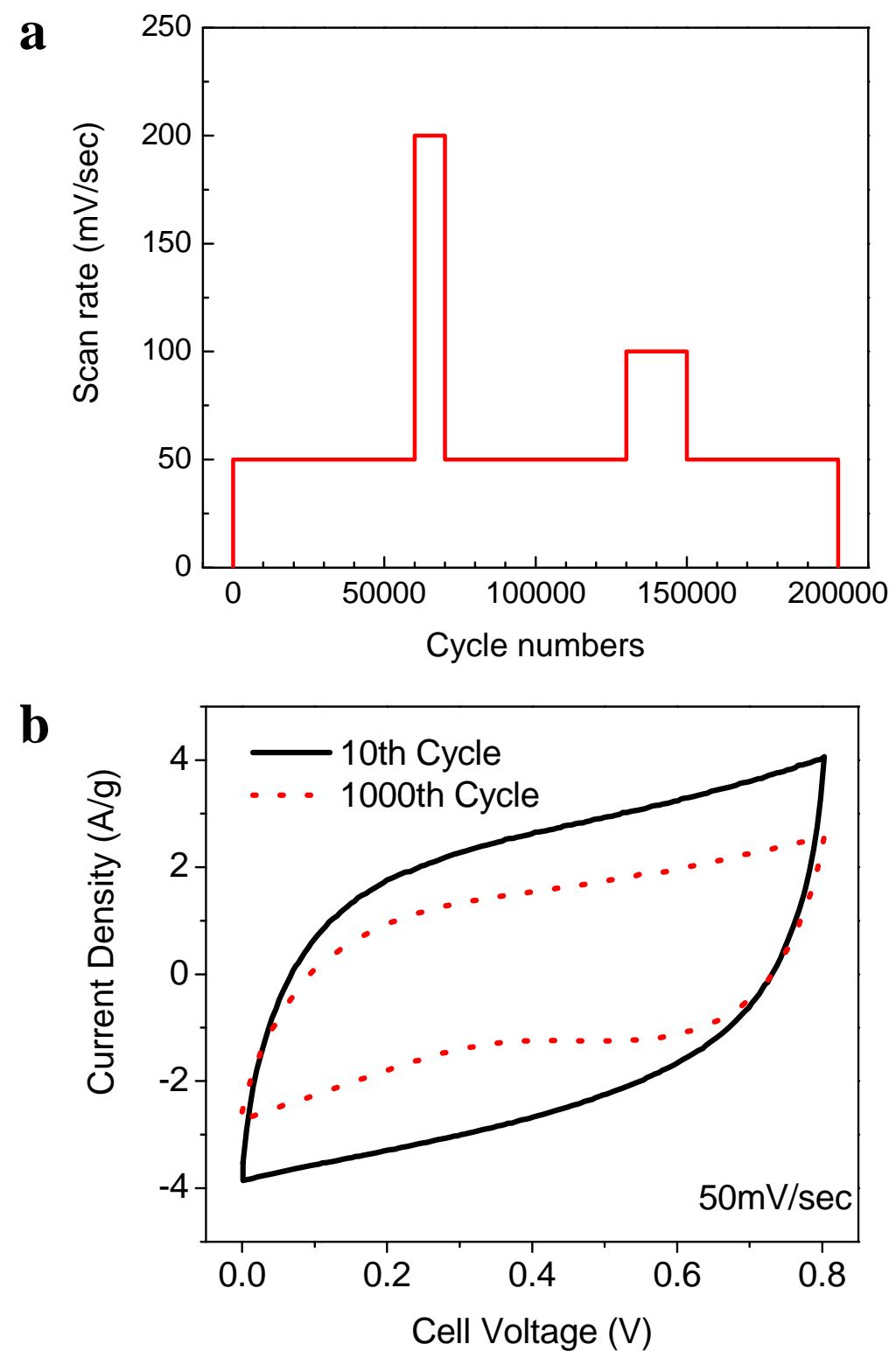

Fig. S14. a, Voltage scan rates used in the long-term cycling tests operated continuously for 200,000 cycles performed for a mixed-valent $\mathrm{MnO}_{\mathrm{x}}$ electrode. b, Cyclic voltammograms of amorphous $\mathrm{MnO}_{2}$ electrode: initial and after $1,000^{\text {th }}$ cycle at a scan rate of $50 \mathrm{mV} / \mathrm{sec}$ showing notable degradation in performance during cycling. 


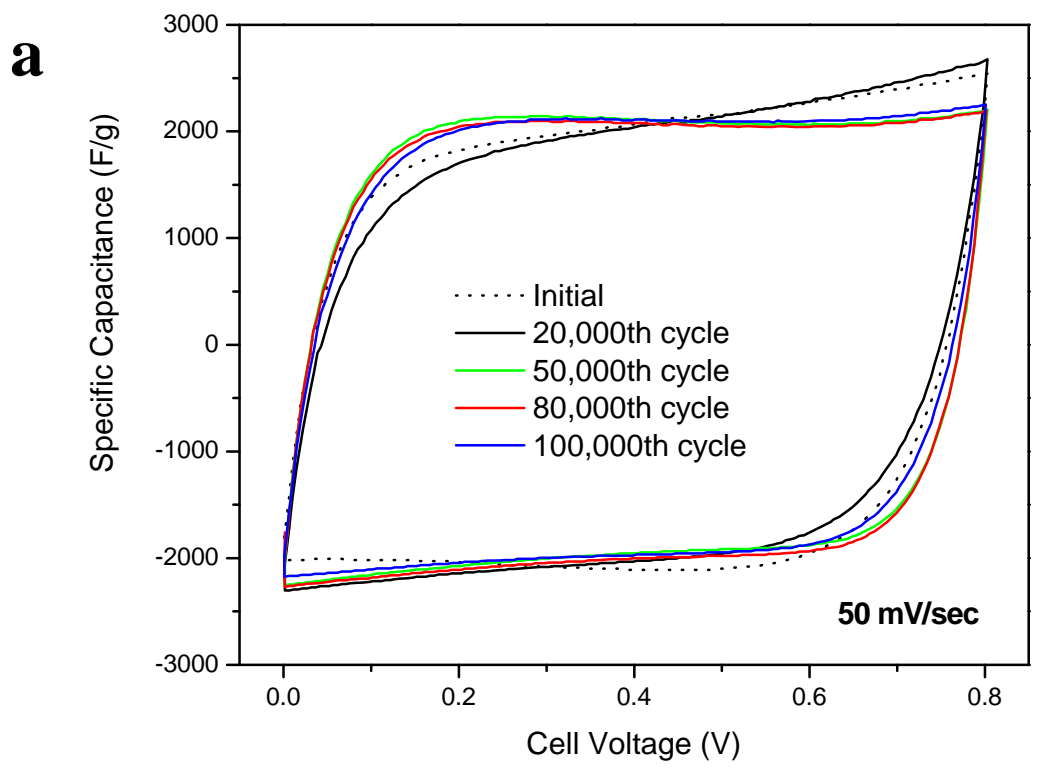

b

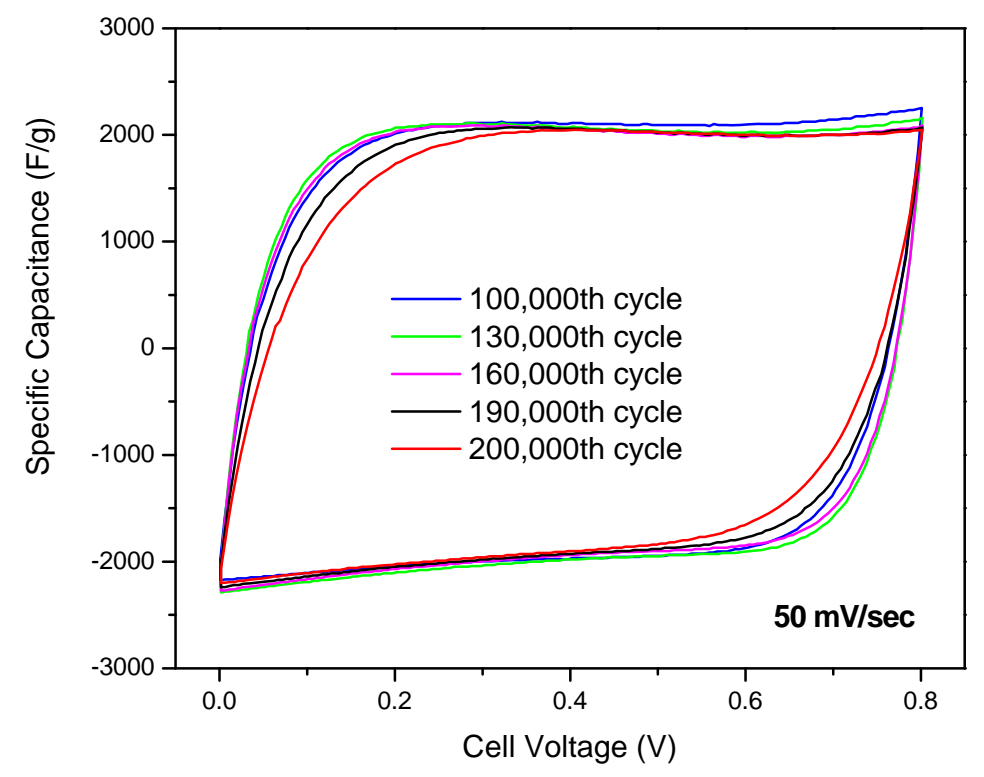

Fig. S15. Cyclic voltammograms of mixed-valent $\mathrm{MnO}_{\mathrm{x}}$ electrode at different cycle numbers (a: initial $\sim 100,000^{\text {th }}$ cycle, $\mathbf{b}: 100,000^{\text {th }} \sim 200,000^{\text {th }}$ cycle) obtained at a scan rate of $50 \mathrm{mV} / \mathrm{sec}$ showing excellent cycling stability. 


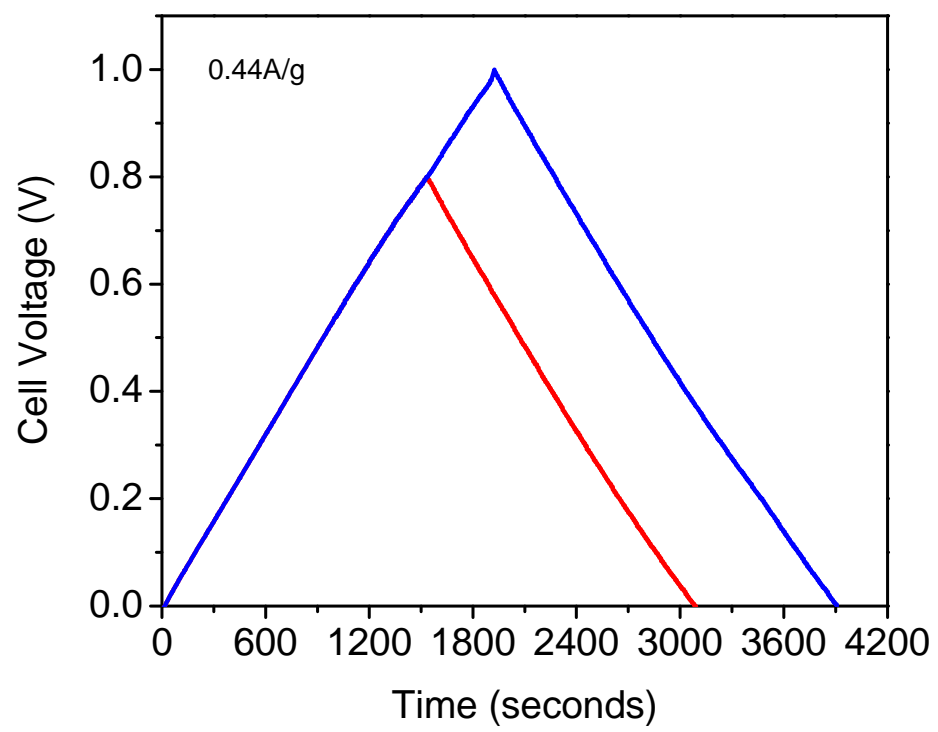

Fig. S16. Typical charge-discharge curves of symmetric pseudocapacitors constructed from mixed-valent $\mathrm{MnO}_{\mathrm{x}}$ electrodes charged up to different voltage. 
a

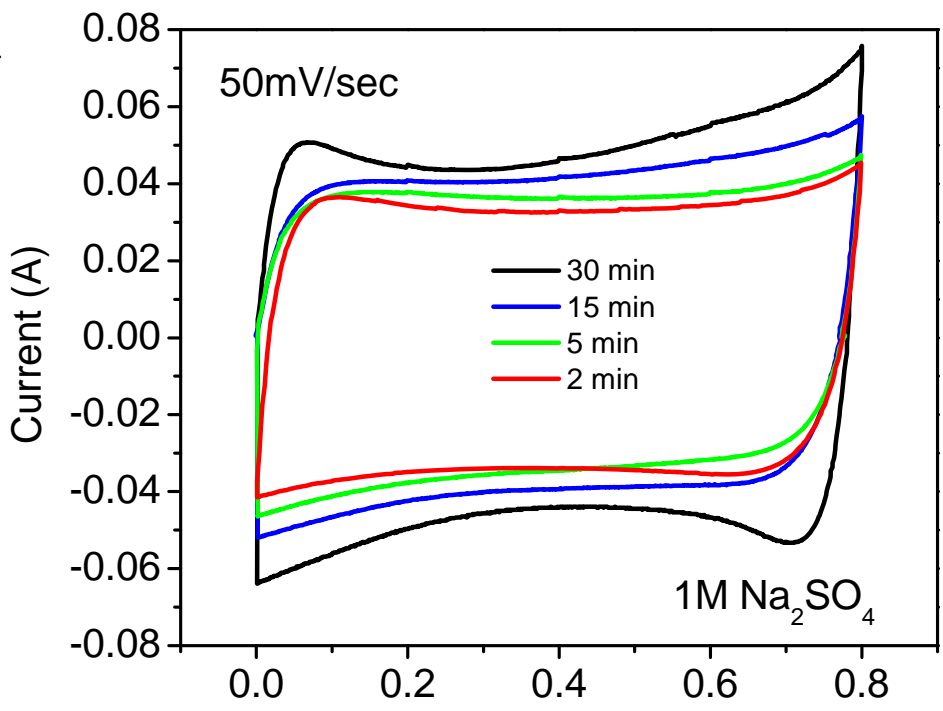

Potential (V vs. SCE)

b

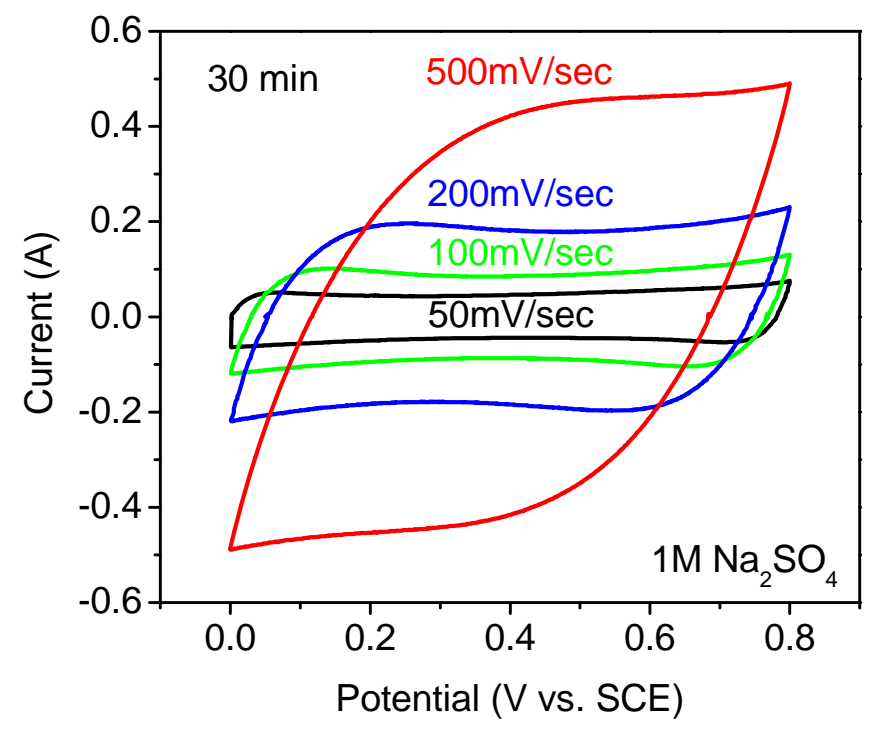

Fig. S17. a, Cyclic voltammograms of mixed-valent $\mathrm{MnO}_{\mathrm{x}} / \mathrm{CFP}$ composite electrodes with different loading amounts of manganese oxide tested in cells with a three-electrode configuration. b, Typical cyclic voltammograms of the $\mathrm{MnO}_{\mathrm{x}} / \mathrm{CFP}$ composite electrodes prepared by deposition of $\mathrm{MnO}_{\mathrm{x}}$ for 30 minutes in $1 \mathrm{M} \mathrm{Na}_{2} \mathrm{SO}_{4}$ solution measured at different scanning rates $(50 \sim 500 \mathrm{mV} / \mathrm{sec})$ using a 3-electrode configuration. 
The potential was measured versus a Saturated Calomel Electrode (SCE) and the measured currents, not the normalized current with respect to the loading amount of $\mathrm{MnO}_{\mathrm{x}}$, are presented. The mixed-valent $\mathrm{MnO}_{\mathrm{x}} / \mathrm{CFP}$ electrode with different loadings of $\mathrm{MnO}_{\mathrm{x}}$ all showed excellent "square-shape" cyclic voltammograms at $50 \mathrm{mV} / \mathrm{sec}$ in $1 \mathrm{M}$ $\mathrm{Na}_{2} \mathrm{SO}_{4}$ solution. The measured currents increased with the loading of $\mathrm{MnO}_{\mathrm{x}}$. For instance, at $0.4 \mathrm{~V}$ (vs. SCE), the measured current of $\mathrm{MnO}_{\mathrm{x}}$ deposited for 5, 15, and 30 minutes showed the $10.7 \%, 26.9 \%$ and $40.9 \%$ increase, compared to current from $\mathrm{MnO}_{\mathrm{x}}$ deposited for 2 minutes. It is noted that even the sample with $\sim 800 \mathrm{~nm}$ thick $\mathrm{MnO}_{\mathrm{x}}$ coating (deposition of $\mathrm{MnO}_{\mathrm{x}}$ for 30 minutes) showed symmetric shape and instant response upon the reversal of voltage, indicating that surface reactions are highly reversible and very fast as shown in Fig. S16 (b). 


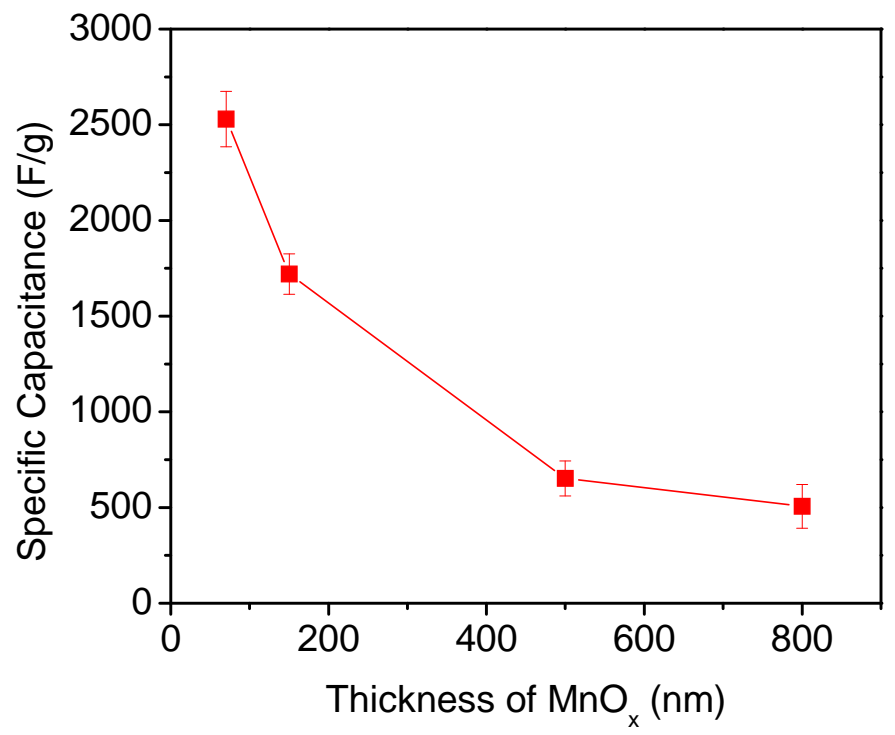

Fig. S18. Specific capacitance (of $\mathrm{MnO}_{\mathrm{x}}$ ) as a function of average thickness of mixedvalent $\mathrm{MnO}_{\mathrm{x}}$ coating deposited for 2 to 30 minutes.

It is noted that the specific capacitance drops with the thickness of the $\mathrm{MnO}_{\mathrm{x}}$ film (or loading), suggesting that only a thin film was fully utilized (or the nano-porous mixedvalent surface phases make dominating contributions to the observed capacitance). To increase the performance of electrochemical capacitors by increasing the $\mathrm{MnO}_{\mathrm{x}}$ film thickness is, perhaps, fundamentally unattainable because the rate capability may ultimately diminish with film thickness. To increase practical energy density of electrochemical capacitors without penalizing high-rate capability, we believe that $\mathrm{MnO}_{\mathrm{x}}$ coatings must be thin to offer the best possible power density. Therefore, one effective approach to increasing practical energy density (e.g. loading) without compromising the specific capacitance or rate capability is to reduce the diameter of the carbon fiber support (or use carbon nanofibers), thus increasing the surface area of CFP for conformal 
coating of $\mathrm{MnO}_{\mathrm{x}}$. It is also noted that, due to the macro-porous feature of CFP and thin, conformal coating of $\mathrm{MnO}_{\mathrm{x}}$ film, scale-up can be easily made by stacking the electrodes up to several layers without compromising excellent performance. We achieved similar performance (within 5\%) with 4 layers stacked without any additional current collectors. 

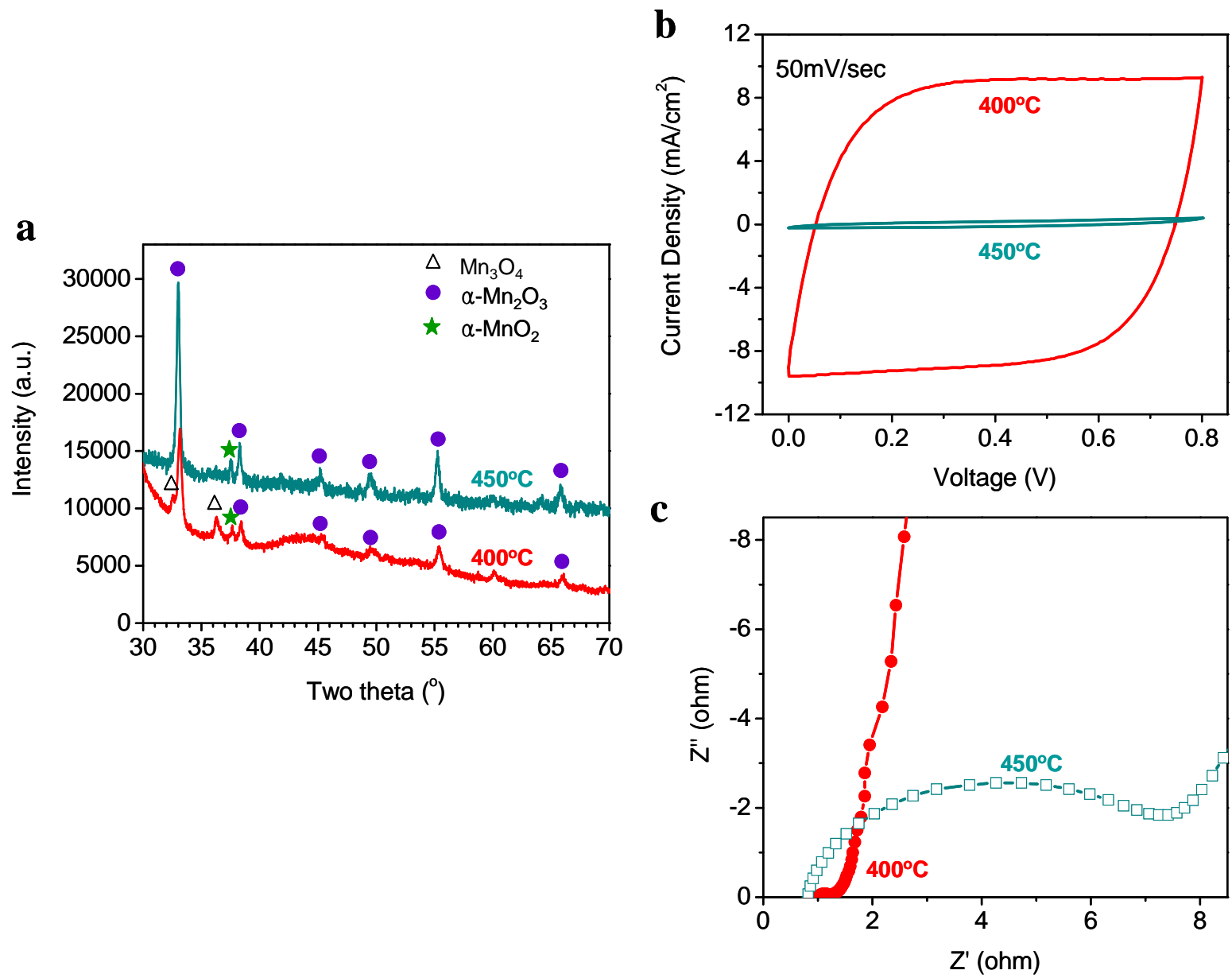

Fig. S19. a, Laboratory $\mathrm{XRD}$ pattern of $\mathrm{MnO}_{\mathrm{x}}$ electrodes annealed at 400 and $450^{\circ} \mathrm{C}$ in air for $2 \mathrm{~h}$. b, Cyclic voltammograms measured at a scan rate of $50 \mathrm{mV} / \mathrm{sec}$ of electrochemical capacitors constructed from electrodes annealed at 400 and $450^{\circ} \mathrm{C}$ in air for $2 \mathrm{~h}$. c, Electrochemical impedance spectra collected at open circuit voltage (OCV) under the influence of an ac voltage of $10 \mathrm{mV}$ for. Fig. (a) shows the $\alpha-\mathrm{Mn}_{2} \mathrm{O}_{3}$ peaks grew at $450^{\circ} \mathrm{C}$ while $\mathrm{Mn}_{3} \mathrm{O}_{4}$ peaks disappeared It agrees well with our observation with in-situ Synchrotron XRD results. Interestingly, performance dropped significantly with increased charge transfer resistance as shown in Fig. (b) and (c). 

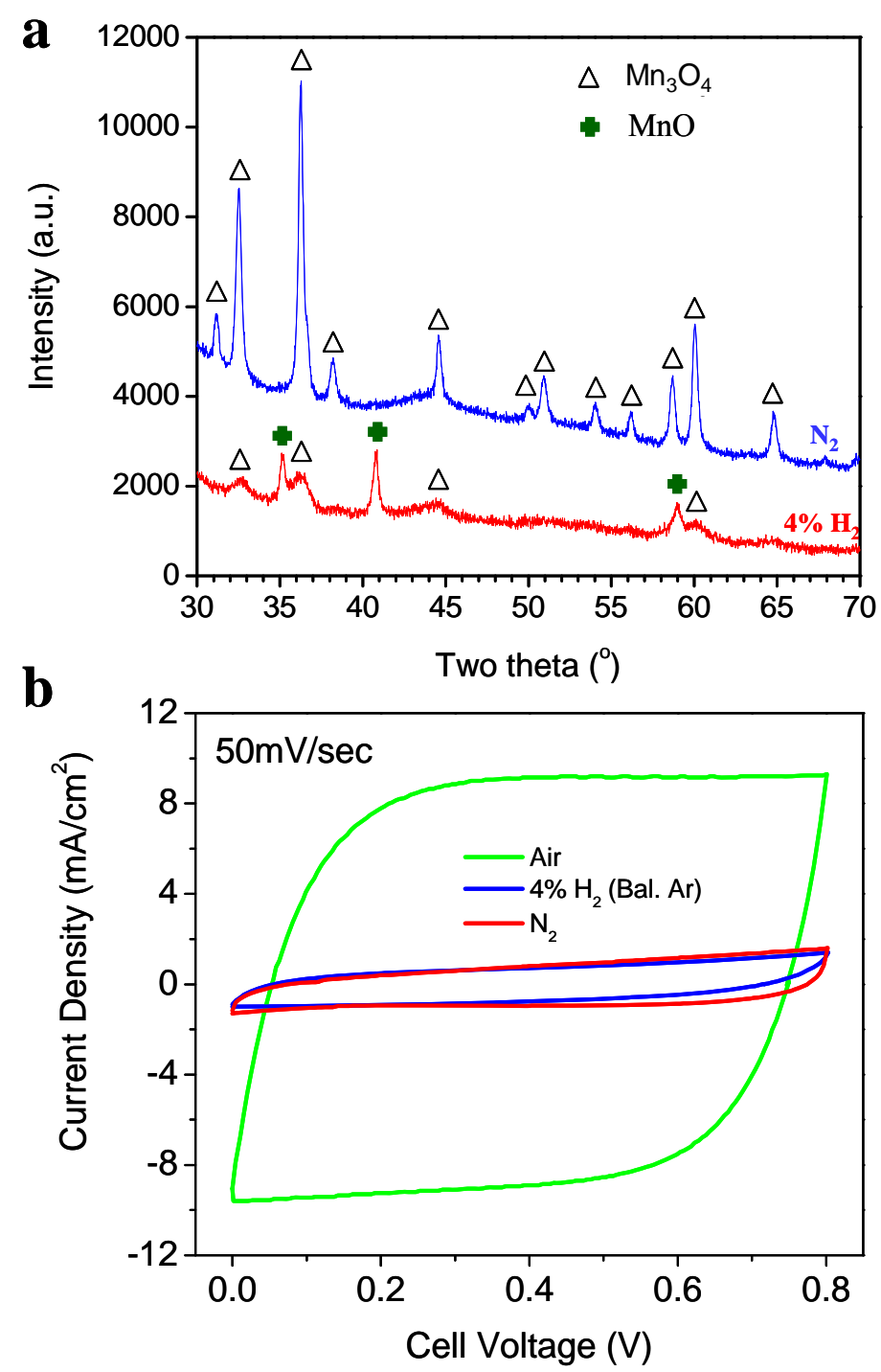

Fig. S20. a, Laboratory XRD pattern of $\mathrm{MnO}_{\mathrm{x}}$ electrodes annealed at $400^{\circ} \mathrm{C}$ in $\mathrm{N}_{2}$ and $4 \%$ $\mathrm{H}_{2}$ (balanced with Ar) for $2 \mathrm{~h}$. b, Cyclic voltammograms measured at a scan rate of $50 \mathrm{mV} / \mathrm{sec}$ of electrochemical capacitors constructed from electrodes annealed at $400^{\circ} \mathrm{C}$ in $\mathrm{N}_{2}$ and $4 \% \mathrm{H}_{2}$ (balanced with Ar) for $2 \mathrm{~h}$. Fig. (a) shows that as-synthesized amorphous $\mathrm{MnO}_{2}$ converted to pure $\mathrm{Mn}_{3} \mathrm{O}_{4}$ when annealed in $\mathrm{N}_{2}$ and even reduced further to form $\mathrm{MnO} / \mathrm{Mn}_{3} \mathrm{O}_{4}$ composite in $4 \% \mathrm{H}_{2}$. The electrochemical performance of these electrodes dropped significantly compared to electrodes annealed in air at $400{ }^{\circ} \mathrm{C}$ for $2 \mathrm{~h}$ as shown in Fig. (b). 

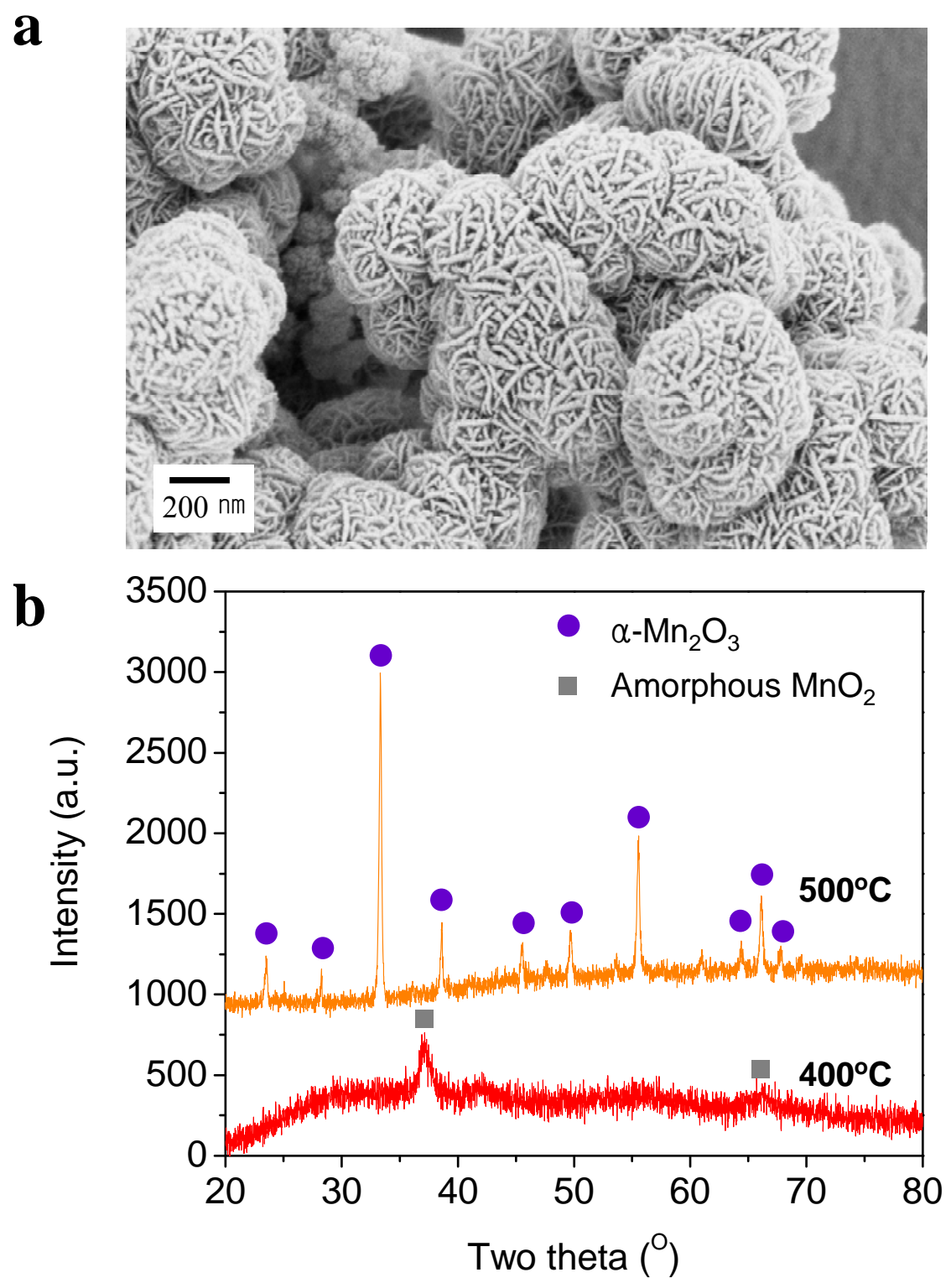

Fig. S21. a, SEM image of powder samples synthesized under the same condition $\left(\mathrm{KMnO}_{4}\right.$ as precursor in $2 \mathrm{M} \mathrm{H}_{2} \mathrm{SO}_{4}$ solution at $\left.75^{\circ} \mathrm{C}\right)$ without carbon fiber paper. $\mathbf{b}$, Laboratory XRD patterns of the powder samples annealed at $400^{\circ} \mathrm{C}$ and $500^{\circ} \mathrm{C}$ in air for $2 \mathrm{~h}$ without carbon fiber paper. Fig. (b) reveals that $\mathrm{MnO}_{2}$ remained amorphous when annealed at $400^{\circ} \mathrm{C}$ in air for $2 \mathrm{~h}$ without carbon, but transformed to crystalline $\alpha-\mathrm{Mn}_{2} \mathrm{O}_{3}$ when annealed at $500^{\circ} \mathrm{C}$ in air for $2 \mathrm{~h}$ without carbon. 
a
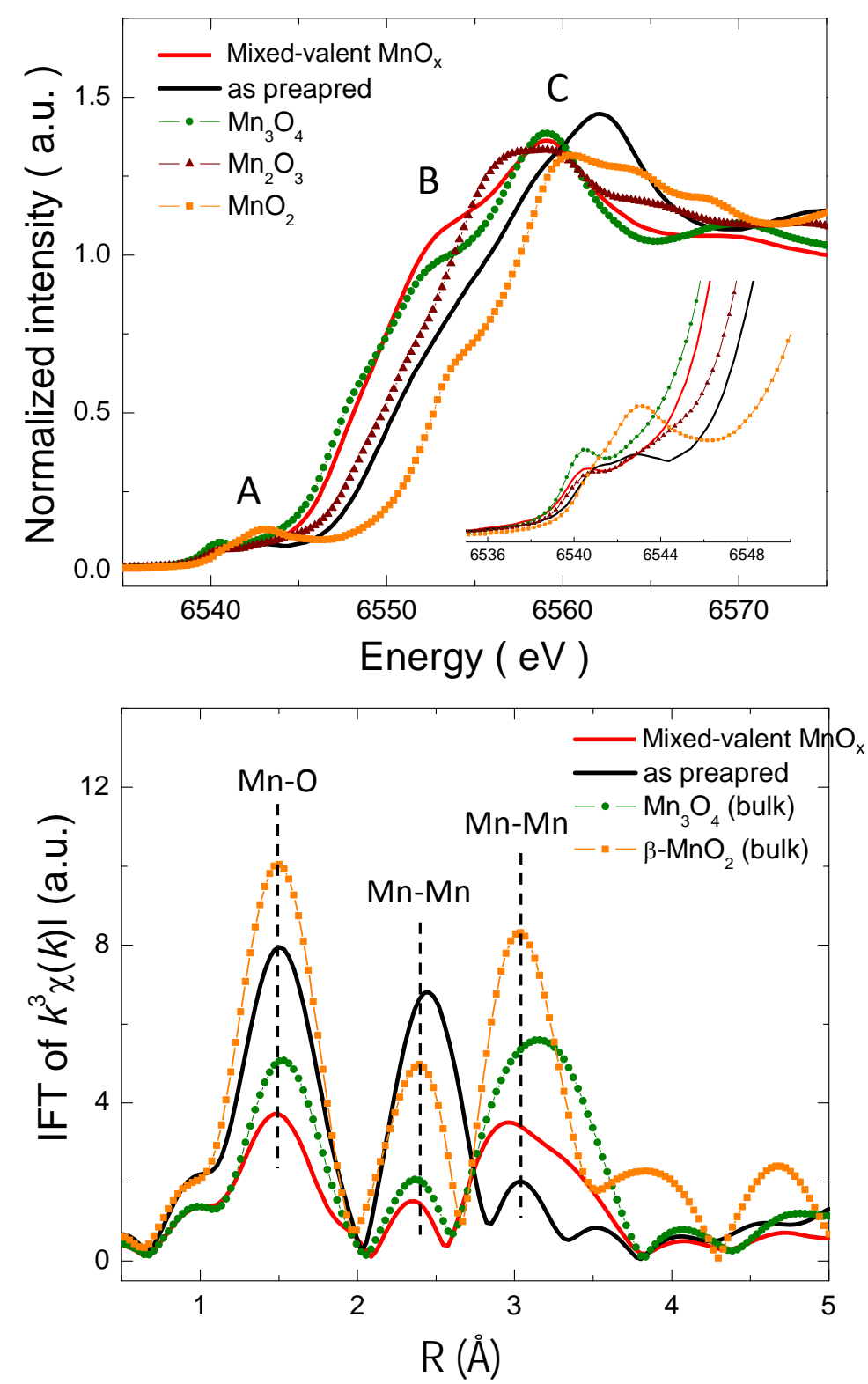

Fig. S22. a, Mn K-edge XANES spectra of the as-prepared and the mixed-valent $\mathrm{MnO}_{\mathrm{x}}$ (heat-treated at $400^{\circ} \mathrm{C}$ in air for $2 \mathrm{~h}$ ) electrodes in comparison with the reference spectra for $\mathrm{Mn}_{3} \mathrm{O}_{4}, \mathrm{Mn}_{2} \mathrm{O}_{3}$ and $\mathrm{MnO}_{2}$. Inset shows the enlargement of the pre-edge region $\mathrm{A}$. $\mathbf{b}$, Fourier transform (FT) magnitude of the $k^{3}$ weighted EXAFS spectra of the as-prepared and the mixed-valent $\mathrm{MnO}_{\mathrm{x}}$ (heat-treated at $400^{\circ} \mathrm{C}$ in air for $2 \mathrm{~h}$ ) electrodes in comparison with the reference $\mathrm{Mn}_{3} \mathrm{O}_{4}$ and $\mathrm{MnO}_{2}$ spectra. The FT was not phase corrected so that the actual bond length may be ca $0.2 \sim 0.4 \AA$ longer. 
We have performed both ex-situ and in-situ X-ray absorption spectroscopy (XAS) to explore the origin of the superior properties of this mixed-valent $\mathrm{MnO}_{\mathrm{x}}$ material. XAS is a very useful tool to probe the changes in valence states (X-ray absorption near edge spectroscopy, XANES) and local coordination (extended X-ray absorption fine structure, EXAFS) of Mn cations in different structures during charge-discharge cycling.

Mn K-edge XANES spectra for the as-prepared (amorphous $\mathrm{MnO}_{2}$ ) and the heattreated (at $400^{\circ} \mathrm{C}$ in air for $2 \mathrm{~h}$ ) $\mathrm{MnO}_{\mathrm{x}} / \mathrm{CFP}$ samples (deposited for 2 minutes) are shown in Fig. S22 in comparison with the reference spectra of several manganese oxides $\left(\mathrm{Mn}_{3} \mathrm{O}_{4}\right.$, $\mathrm{Mn}_{2} \mathrm{O}_{3}$ and $\mathrm{MnO}_{2}$ ). Both the XANES and Fourier transform (FT) magnitude of the EXAFS spectrum reveal that the as-prepared manganese oxide has a layered K-birnessite $\left(\mathrm{K}_{\mathrm{x}} \mathrm{MnO}_{2}\right.$ ) type-structure with mixed $\mathrm{Mn}^{3+} / \mathrm{Mn}^{4+}$ ions. In contrast, the heat-treated (at $400^{\circ} \mathrm{C}$ in air for $2 \mathrm{~h}$ ) manganese oxide has an average electronic and local structure similar to those of $\mathrm{Mn}_{3} \mathrm{O}_{4}$. It agrees very well with our synchrotron-based XRD analyses, which showed that the bulk phase of the heat-treated, mixed-valent $\mathrm{MnO}_{\mathrm{x}}$ (deposited for 2 minutes) was $\mathrm{Mn}_{3} \mathrm{O}_{4}$. Average $\mathrm{Mn}$ valances for the as-prepared (amorphous $\mathrm{MnO}_{2}$ ) and the heat-treated (mixed-valent $\mathrm{MnO}_{\mathrm{x}}$ ) samples were estimated to be $\sim 3.3$ and $\sim 2.7$ by comparing the XANES edge positions at half height with those for the reference Mn oxides.

The most interesting difference between the as-prepared and the heat-treated sample is in the main edge absorption feature $\mathrm{B}$, which is assigned to a shakedown process involving the $1 \mathrm{~s}$ to $4 \mathrm{p}$ transition followed by ligand-to-metal charge transfer (LMCT) $)^{9,10}$, or in other words, a hole state redistribution toward the oxygen sites, as an indicator for the degree of covalent character by the $\mathrm{Mn}(3 \mathrm{~d})-\mathrm{O}(2 \mathrm{p})$ bond. Feature B is not observed in 
the as-prepared sample but very strong for the heat-treated sample with even higher intensity than the $\mathrm{Mn}_{3} \mathrm{O}_{4}$ reference, indicating increased covalent bond character between the $\mathrm{Mn}(3 \mathrm{~d})-\mathrm{O}(2 \mathrm{p})$ bond in the heat-treated material, which is quite important and will be further discussed in the in-situ XANES results later. It should be noted that the heattreated sample is also quite different from the $\mathrm{Mn}_{3} \mathrm{O}_{4}$ sample in the pre-edge feature $\mathrm{A}$, which is partially allowed because of electric quadrupole coupling and/or 3d-4p orbital mixing arising from the non-centrosymmetric environment in the Mn-O coordination. The weaker intensity in feature A shows that the heat-treated sample has less tetrahedral sited $\mathrm{Mn}$ than the bulk $\mathrm{Mn}_{3} \mathrm{O}_{4}$ reference, which is further supported by the Fourier transformed EXAFS in Fig. S22 (B), indicating that significant structural differences exist between heat-treated sample (i.e., mixed-valent $\mathrm{MnO}_{\mathrm{x}}$ ) and the bulk $\mathrm{Mn}_{3} \mathrm{O}_{4}$ reference.

The Fourier transformed magnitude of EXAFS spectrum for the heat-treated sample (mixed-valent $\mathrm{MnO}_{\mathrm{x}}$ ) shows much smaller intensity in the first three shells located around 1.5, 2.2 and $3.1 \AA$ corresponding to $\mathrm{Mn}-\mathrm{O}, \mathrm{Mn}-\mathrm{Mn}$, and overlapped $\mathrm{Mn}-\mathrm{O}$ and Mn-Mn contribution in the $\mathrm{Mn}_{3} \mathrm{O}_{4}$ structure. The decreased FT peak intensity could be due to the $\mathrm{Mn}$ defects in the $\mathrm{Mn}-\mathrm{O}_{4}$ tetrahedral sties of $\mathrm{Mn}_{3} \mathrm{O}_{4}$ structure and broad distribution of Mn-O and Mn-Mn bond lengths due to the mixed Mn valance character of the mixed-valent $\mathrm{MnO}_{\mathrm{x}}$. In addition, the slightly shorter $\mathrm{Mn}-\mathrm{O}$ distance of the mixedvalent $\mathrm{MnO}_{\mathrm{x}}$ than $\mathrm{Mn}_{3} \mathrm{O}_{4}$ is due to either the increased covalent bonding character between Mn (3d) and O (2p) orbitals or the existence of Mn-O coordinations in the $\mathrm{Mn}_{2} \mathrm{O}_{3}$ and $\mathrm{MnO}_{2}$ like environments in line with the mixed valance state of $\mathrm{Mn}$ ions in the mixed-valent $\mathrm{MnO}_{\mathrm{x}}$. 
These unique XANES and EXAFS data implies that the mixed-valent $\mathrm{MnO}_{\mathrm{x}}$ (the heat-treated sample) has unique structure with totally different Mn cation site distribution and electronic structure (e.g. covalent bond character between $\mathrm{Mn}$ and $\mathrm{O}$ ions) than all of the bulk reference manganese oxides (such as $\mathrm{Mn}_{3} \mathrm{O}_{4}, \mathrm{Mn}_{2} \mathrm{O}_{3}$, and $\mathrm{MnO}_{2}$ ) due to the mixed valence state of manganese ions (e.g., $\mathrm{Mn}^{2+}, \mathrm{Mn}^{3+}$ and $\mathrm{Mn}^{4+}$ ) created during the heat-treatment process. 

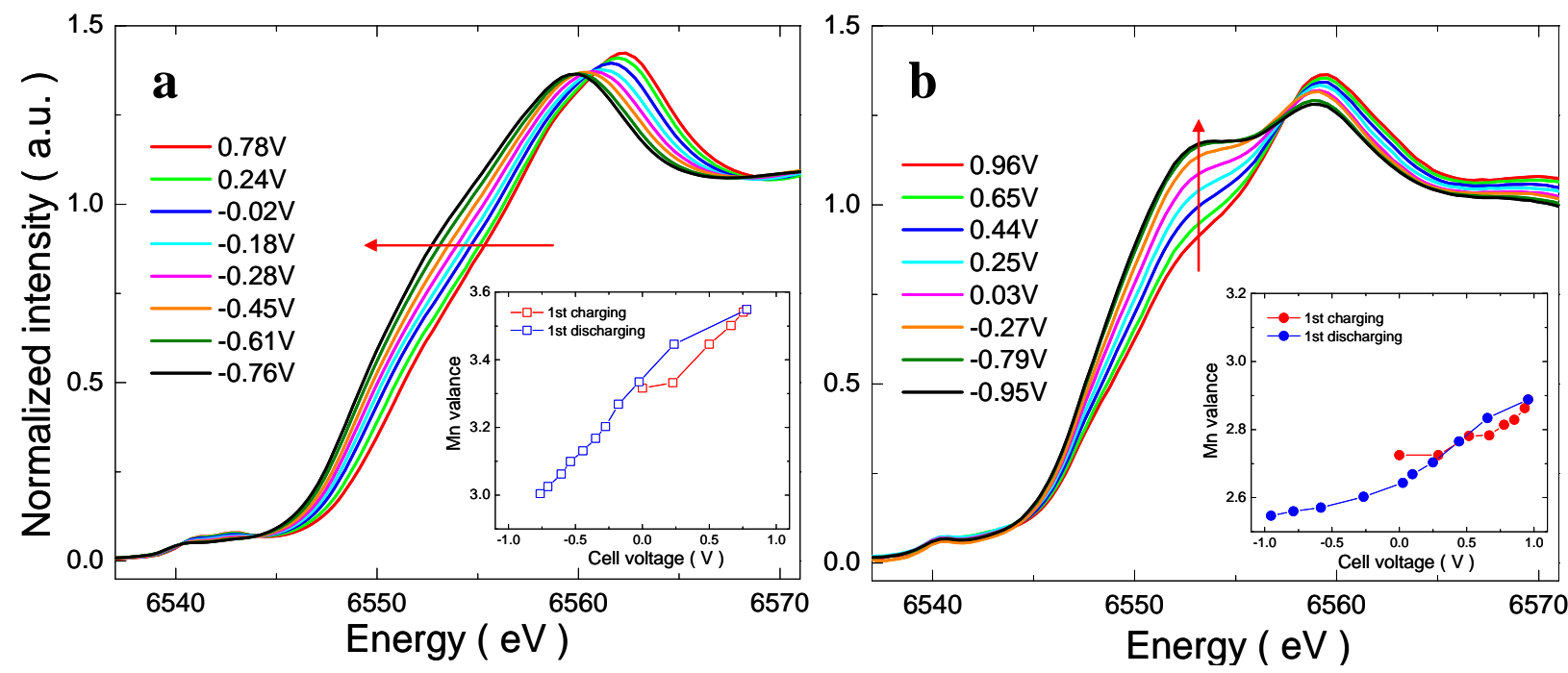

Fig. S23. XANES spectra of the positive electrodes in the in-situ (symmetric) cell for a, the as-prepared and $\mathbf{b}$, mixed-valent $\mathrm{MnO}_{\mathrm{x}}$ electrode during discharge in $1 \mathrm{M} \mathrm{Na} \mathrm{SO}_{4}$ electrolyte.

To directly correlate the oxidation state of $\mathrm{Mn}$ ions with the capacitance or electrochemical state of the electrode in a capacitor, we performed in-situ Mn K-edge fluorescence X-ray absorption spectroscopy (XAS) to probe the local atomic and electronic structural change of the as-synthesized sample (amorphous $\mathrm{MnO}_{2}$ ) and the heat-treated sample (mixed-valent $\mathrm{MnO}_{\mathrm{x}}$ ) as a function of the applied potential in $1 \mathrm{M}$ $\mathrm{Na}_{2} \mathrm{SO}_{4}$. Fig. S23 shows the in-situ XANES spectra for the as-prepared and the heattreated electrodes during the $1^{\text {st }}$ discharge (positive electrode in the in-situ cell). The voltage window for the cell using the as-prepared electrodes was cycled in a narrower $(+0.8$ to $-0.8 \mathrm{~V})$ range than that $(+1.0$ to $-1.0 \mathrm{~V})$ for the cell using the heat-treated electrodes, due to the oxygen evolution reaction at voltage over $+0.8 \mathrm{~V}$. The cells were 
discharged below $0.0 \mathrm{~V}$ to monitor full ranges of the valence state changes at the positive electrodes. For the as-prepared sample, the XANES spectra showed entire edge shift towards the lower energy position in a continuous manner during the discharge process, revealing that the charge storage mechanism is mostly attributed to the $\mathrm{Mn}^{3+} / \mathrm{Mn}^{4+}$ redox reactions on Mn sites. This is typical for most of the Mn K-edge XANES changes of manganese oxides for pseudocapacitors, which agrees well with the common belief that the charge compensation for the incorporation/extraction of cations into the $\mathrm{MnO}_{2}$ occurs in the $\mathrm{Mn}$ site by the redox reactions between $\mathrm{Mn}^{3+}$ and $\mathrm{Mn}^{4+}$ ions.

However, we have noticed that, quite interestingly, the XANES spectra for the heat-treated sample (mixed-valent $\mathrm{MnO}_{\mathrm{x}}$ ) showed completely different spectral feature changes during the discharge, which have never before been reported. Shown in Fig. S23 (b), slight edge shift towards lower energy was observed, indicating the decrease of average oxidation state of $\mathrm{Mn}$ ions. However, there is no obvious entire edge shift during discharge as observed for the as-prepared electrode. Instead, we observed a unique evolution of the B peak, which is related to the ligand-to-metal charge transfer process. The increased B peak intensity indicates the increased degree of covalent character of $\mathrm{Mn}(3 \mathrm{~d})-\mathrm{O}(2 \mathrm{p})$ bonding during discharge. Therefore, the unique Mn K-edge change in the form of increasing $\mathrm{B}$ feature clearly shows that a large portion of the charge compensation during discharge might be originated from the hole state redistribution towards the oxygen sites, rather than just the decreasing number of $\mathrm{Mn}^{4+}$ at the $\mathrm{Mn}$ sites (as in the case of the as-prepared sample). Although small intensity change of B feature in XANES spectra during charge-discharge had been reported in the literature ${ }^{11,12}$ for transition metals such as Co and Mn, it has never before been observed that this spectral 
change plays a dominating role over the edge shift. The role of oxygen anions in transition metal oxides for charge compensation was previously argued for lithium battery electrodes. Aydinol et al. showed that, in their $a b$ initio study, more charge can be transferred to the oxygen anions upon intercalation of lithium ions than to the metal cations in the oxide ${ }^{13}$. In our in-situ synchrotron XAS experiments, we have monitored that the charge compensation for the electron exchange can be achieved at oxygen site as well as Mn site, which has never before been reported for pseudocapacitor electrodes. The unique atomic and electronic structure of the nanostructured, mixed-valent $\mathrm{MnO}_{\mathrm{x}}$ may allow this additional charge compensation mechanism which is not observed in $\mathrm{MnO}_{2}$.

As shown in the inset of Fig. S23, although the heat-treated sample of mixedvalent $\mathrm{MnO}_{\mathrm{x}}$ showed much higher capacitance than the as-prepared material, the average Mn valance change within the 0.8 to $0.0 \mathrm{~V}$ window calculated from the edge shift is estimated to be $\sim 0.3 \mathrm{e}$ which is similar for the as-prepared material within the 0.8 to $0.0 \mathrm{~V}$ window. The observed valence change of $\mathrm{Mn}$ ion cannot account for the large pseudocapacitance observed experimentally. This result provides a further support to the hypothesis that the large portion of the charge compensation during discharge might be originated from the hole state redistribution towards oxygen sites. If the oxygen anions in a metal oxide can indeed provide additional charge composition mechanism, it will open a new approach to design and synthesis of new electrode materials with greater capacity for supercapacitors and batteries.

DFT-based calculation also support the evidence that the observed capacitances of our nanoporous multi-phase, multi-valent $\mathrm{MnO}_{\mathrm{x}}$ are due to the amount of charge 
accumulated at $\mathrm{O}$ sites and surfaces. Our state-of-the-art DFT+U calculations indeed show that, while Mn cations act as attractors of negative charge, the surface and $\mathrm{O}$ subnetwork constitute regions where the excess negative charge can be further deposited. In $\mathrm{Mn}_{3} \mathrm{O}_{4}$, charge accumulation at $\mathrm{O}$ centers and surface seems to result from the delicate balance of the geometrical features of the crystal and the electronic coupling between $3 \mathrm{~d}$ and $2 \mathrm{p}$ states of the $\mathrm{Mn}$ and $\mathrm{O}$ ions. A deeper understanding of the delicate competition between structure, electronic properties, and surface effects leading to the charge storage ability of manganese oxides is needed and further computations are at present in progress to elucidate these critical issues. 


\section{Supplementary References}

1. Chmiola, J.; Yushin, G.; Gogotsi, Y.; Portet, C.; Simon, P.; Taberna, P. L. Science 2006, 313, (5794), 1760-1763.

2. Korenblit, Y.; Rose, M.; Kockrick, E.; Borchardt, L.; Kvit, A.; Kaskel, S.; Yushin, G. ACS Nano 2010, 4, (3), 1337-1344.

3. $\quad$ Kresse, G.; Furthmuller, J. Physical Review B 1996, 54, (16), 11169-11186.

4. Kresse, G.; Joubert, D. Physical Review B 1999, 59, (3), 1758-1775.

5. Perdew, J. P.; Burke, K.; Ernzerhof, M. Physical Review Letters 1996, 77, (18), 3865-3868.

6. Dudarev, S. L.; Botton, G. A.; Savrasov, S. Y.; Humphreys, C. J.; Sutton, A. P. Physical Review B 1998, 57, (3), 1505-1509.

7. Franchini, C.; Podloucky, R.; Paier, J.; Marsman, M.; Kresse, G. Physical Review B 2007, 75, (19).

8. Bader, R. F. W., Atoms in Molecules - A Quantum Theory. Oxford University Press: 1990.

9. Kim, M. G.; Yo, C. H. J. Phys. Chem. B 1999, 103, (31), 6457-6465.

10. Horne, C. R.; Bergmann, U.; Grush, M. M.; Perera, R. C. C.; Ederer, D. L.; Callcott, T. A.; Cairns, E. J.; Cramer, S. P. J. Phys. Chem. B 2000, 104, (41), 9587-9596.

11. Yoon, W. S.; Balasubramanian, M.; Chung, K. Y.; Yang, X. Q.; McBreen, J.; Grey, C. P.; Fischer, D. A. J. Am. Chem. Soc. 2005, 127, (49), 17479-17487.

12. Kim, M. G.; Shin, H. J.; Kim, J. H.; Park, S. H.; Sun, Y. K. J. Electrochem. Soc. 2005, 152, (7), A1320-A1328.

13. Aydinol, M. K.; Kohan, A. F.; Ceder, G.; Cho, K.; Joannopoulos, J. Physical Review B 1997, 56, (3), 1354-1365. 